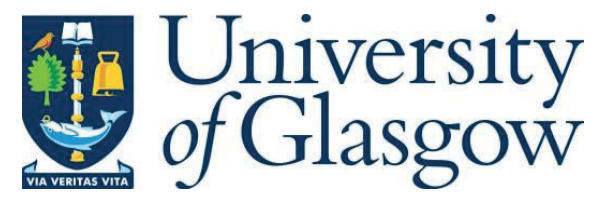

Gao, Z. and Cai, H. (2021) Effect of total stress path and gas volume change on undrained shear strength of gassy clay. International Journal of Geomechanics, 21(11), (doi: 10.1061/(ASCE)GM.1943-5622.0002198).

This is the author's final accepted version.

There may be differences between this version and the published version. You are advised to consult the publisher's version if you wish to cite from it.

http://eprints.gla.ac.uk/245616/

Deposited on: 08 July 2021

Enlighten - Research publications by members of the University of Glasgow http://eprints.gla.ac.uk 
4 Abstract: Clay with free gas bubbles can be frequently encountered in the seabed. Gassy clay

\section{Effect of total stress path and gas volume change on undrained shear strength of gassy clay}

\author{
Zhiwei $\mathrm{Gao}^{1}$ and Hongjian Cai ${ }^{2}$
}

\begin{abstract}
is an unsaturated soil but its mechanical behaviour cannot be described using conventional
\end{abstract} unsaturated soil mechanics because it has a composite internal structure with a saturated soil matrix and gas bubbles. The gas bubbles can have either a detrimental or beneficial effect on the undrained shear strength of clay. New lower and upper bounds for the undrained shear strength of gassy clay is derived by considering the effect of total stress path and plastic hardening of the saturated soil matrix. For the upper bound, it is assumed that there is only bubble flooding and the shear strength of an unsaturated soil sample is the same as that of the saturated soil matrix. Bubble flooding makes the saturated soil matrix partially drained and increases the undrained shear strength. The amount of bubble flooding is calculated using the Modified Cam-Clay model and Boyle's law for ideal gas. The lower bound is derived based on the assumption that the entire soil fails without bubble flooding and the gas cavity size evolves due to plastic hardening of the saturated soil matrix. Compared to Wheeler's upper and lower bounds which do not consider plastic hardening of the saturated soil matrix, the new theoretical results give a better prediction of the undrained shear strength of gassy clays, especially for the upper bound. Implications for constitutive modelling of gassy clay is discussed based on the new research outcomes.

Keywords: Gassy clay; critical state; undrained shear strength; triaxial compression; upper and lower bounds

\footnotetext{
1 Senior Lecturer. James Watt School of Engineering, University of Glasgow, Glasgow, G12 8QQ, UK. Corresponding author. Email: zhiwei.gao@glasgow.ac.uk. Tel: +44 1413303927

2 PhD student. James Watt School of Engineering, University of Glasgow, Glasgow, G12 8QQ, UK.
} 
Fine-grained soils containing large gas bubbles can be frequently encountered in the seabed (Gao et al., 2020; Hong et al., 2020; Hong et al., 2017; Jommi et al., 2019; Sultan and Garziglia, 2014). The gas is typically methane produced biogenically or thermochemically (Sills et al., 1991; Sills \& Wheeler, 1992; Sultan et al., 2012; Wheeler et al., 1990). The gas bubbles can have a dramatic influence on the mechanical response of soils such as compressibility and undrained shear strength. Fig. 1 shows the internal structure of gassy clay. The gas bubbles fit inside the saturated clay matrix, rather than the pore water. Therefore, the gas phase is discontinuous, and the water phase is continuous. The conventional unsaturated soil mechanics is not suitable for describing the response of gassy clay because it has been developed for soils with continuous gas phase and discontinuous water phase, like soils on the embankment slopes. Gassy clays are essentially composite materials with three phases: the soil skeleton, pore water and gas bubbles (Wheeler, 1986). The interaction between gas bubbles and saturated soil matrix governs the stress-strain relationship of the soil. Generally, the gas bubbles increase the compressibility of gassy soils due to their low bulk modulus (Thomas, 1987; Wheeler, 1986; Hong et al., 2017). But they can either increase or decrease the undrained strength of fine-grained soils, which is associated with the unique internal structure of the soil (Fig. 1). The gas bubbles are much larger than the soil particles and fit within the saturated soil matrix. The gas bubbles occupy the entire cavities when there is no bubble flooding (Fig. 1a). In this case, these bubbles are like the cavities in solids (e.g., concrete or steel) which have a damaging effect on the soil strength. In some cases, however, the pore water can drain into the cavities (Fig. 1b), which is called 'bubble flooding' (Wheeler, 1986; Wheeler, 1988a, 1988b; Sills et al., 1991). Bubble flooding makes the saturated soil matrix partially drained in a globally undrained test (no water flow in or out of the sample at the boundary) and the undrained shear strength increase.

There has been extensive research on the undrained shear strength of gassy fine-grained soils. Wheeler (1986) was the first to derive the upper and lower bounds for the undrained shear strength of gassy clays. The upper bound was derived based on the assumption that the bubbles are completely flooded by the pore water in an undrained test. For the lower bound, it is assumed that the entire saturated soil matrix reaches failure and no bubble flooding occurs. This theory is capable of giving the maximum and minimum possible undrained shear 
strength of gassy clays (Wheeler, 1986; Sham, 1989; Hong et al., 2017). But it has some limitations when used for specific tests. The upper bound tends to overestimate the beneficial effect of gas bubbles on the soil strength because complete bubble flooding is not possible if the gas dissolution in pore water is negligible. When the gas cavities were completely flooded, the gas volume would become zero and the gas pressure would reach infinite if the free gas does not dissolve in the pore water. Since the soil considered as a rigid-perfectly-plastic material, the lower bound can underestimate the soil strength when there is significant compression of gas bubbles during loading (Sultan et al., 2012). Compression of gas bubbles reduces the volume fraction of free gas in the soil. Theoretical analysis has shown than the undrained shear strength of gassy clay is higher when the gas volume fraction is lower under otherwise identical conditions (Wheeler, 1986; Sham, 1989). Besides, the upper and lower bounds were derived without considering the total stress path. But the total stress path can affect the change of pore water pressure, which is found to have a dramatic influence on soil strength (Wheeler, 1986; Sham, 1989; Hong et al., 2020; Gao et al., 2020). Some constitutive models have also been proposed for gassy clay, which can be used to predict the undrained shear strength of this soil (Pietruszczak \& Pande, 1996; Grozic et al., 2005; Sultan and Garziglia, 2014; Hong et al., 2020; Gao et al., 2020). But some model parameters which are not easy to determine are needed.

A new study on the upper and lower bounds for the undrained shear strength under specific loading conditions is presented based on the work by Wheeler (1986) and the critical state soil mechanics (Muir Wood, 1990). It is assumed that there is only bubble flooding for the upper bound, but complete bubble flooding does not occur. The amount of bubble flooding the one in Wheeler (1986) but the volume change of gas cavities during loading is considered. The effect of overconsolidation and total stress path is accounted for based on the Modified Cam-Clay (MCC) model (Roscoe \& Burland, 1968). The new upper and lower bounds have been validated by the test data on three gassy clays. Implications for constitutive modelling is discussed. This study only focuses on the behaviour of normally consolidated and lightly overconsolidated clays, which are frequently seen in the seabed. The effective mean effective stress $p^{\prime}$ is defined as the difference between the total mean stress $p$ and pore water pressure $u_{w}$. 


\section{The new upper and lower bounds}

91 For the new upper and lower bounds, the same assumption for the soil structure as that in Wheeler (1986) is used. Specifically, the soil is a composite material with a saturated soil matrix and compressible gas cavities. The gas bubbles tend to degrade the soil structure and shear strength when there is no bubble flooding. But they can be flooded by the pore water from the saturated soil matrix in some cases, making the undrained shear strength higher. It is assumed that there is only bubble flooding for the upper bound. No bubble flooding occurs for the lower bound, indicating that the bubbles only have a detrimental effect on soil strength (Wheeler, 1986). The initial stress state is assumed to be isotropic for the derivation below. It should be emphasized that the new upper and lower bounds are not the rigorous upper and lower bounds that consider all the loading conditions (Wheeler, 1986). Instead, they are derived for each specific loading condition and expected to offer a better approximation of the real undrained shear strength than the theory of Wheeler (1986).

\section{The upper bound}

In the original work by Wheeler (1988), the upper limit of the undrained shear strength was derived based on complete bubble flooding which can be written as Eq (1).

$$
\frac{s_{u}}{s_{u}^{s}}=\frac{3\left\{1-\left[f_{0} /\left(1-f_{0}\right)\right]^{\frac{1}{3}}\right\}}{3-2\left[f_{0} /\left(1-f_{0}\right)\right]^{\frac{1}{4}}} \exp \left[\frac{\left(1+e_{m 0}\right) f_{0}}{\lambda\left(1-f_{0}\right)}\right]
$$

where $e_{m 0}$ is the initial void ratio of matrix.

This is unrealistic and tends to give significant overestimation of the soil strength in some cases. The following assumptions are made for deriving the new upper bound:

(a) The stress and strain state in the soil is uniform.

(b) There is no gas dissolution in the pore water when the pore pressure increases or more free gas generation when the pore water pressure decreases. Boyle's law can be used to describe the volume change of gas bubbles. The gas pressure remains finite and the gas volume is not zero at the failure state. Note that gas dissolution in the pore water gives extra volume contraction of the saturated soil matrix, which increases the undrained shear strength. Rigorously speaking, this should be 
considered in the upper bound. But this is very small in most cases and neglected here.

(c) The gas pressure $u_{g}$ is always identical to the pore water pressure $u_{w}$, which is the condition for bubble flooding (Wheeler, 1986; Sham, 1989). The gas volume change is only due to bubble flooding, which is the same as the volume change of the saturated soil matrix. The volume of the cavity remains the same during bubble flooding;

(d) For the unsaturated soil, the undrained shear strength of the entire soil sample is the same as that of the saturated matrix after bubble flooding. The existence of free gas at the failure state does not damage the soil structure. Note that the derivation of the upper bound in Wheeler (1986) has accounted for this damaging effect but it can still be very high for some tests. This indicates that proper consideration of the amount of bubble flooding is more important.

Based on the Boyle's law and Assumptions (b) and (c), one can get

$$
\left(u_{w}^{0}+p_{a}\right) V_{g}^{0}=\left(u_{w}^{f}+p_{a}\right) V_{g}^{f}
$$

where $V$ and $u$ denote the specific volume (calculated by assuming that the volume of soil particles is unit) and pressure, respectively; the subscripts ' $\mathrm{g}$ ' and ' $\mathrm{w}$ ' denote gas and pore water, respectively; the superscripts ' 0 ' and ' $f$ ' represent the initial and failure states, respectively; $p_{a}$ is the atmospheric pressure $(101 \mathrm{kPa})$. At the initial state, the gas volume is

$$
V_{g}^{0}=\frac{f_{0}}{1-f_{0}} V_{m}^{0}=\frac{f_{0}}{1-f_{0}}\left(1+e_{m}^{0}\right)
$$

where $f_{0}$ is the initial gas volume fraction (Wheeler, 1986); $V_{m}^{0}$ is the initial specific volume of the saturated matrix and $e_{m}^{0}$ is the initial matrix void ratio (Wheeler, 1986). If the initial stress state of the soil is isotropic and the stress state is uniform in the soil (Assumption a), the pore water pressure at the failure state can be obtained as below based on the Modified Cam-Clay (MCC) model (Fig. 2)

$$
u_{w}^{f}=p_{0}^{\prime}+u_{w}^{0}+\frac{1}{a} M p_{f}^{\prime}-p_{f}^{\prime}
$$


144 where $p_{0}^{\prime}\left(=p_{0}-u_{w}^{0}\right)$ is the initial mean effective stress, $p_{f}^{\prime}\left(=p_{f}-u_{w}^{f}\right)$ is the mean 145 effective stress at failure, $M$ is the critical state stress ratio and $a$ denotes the slope of the 146 total stress path (Fig. 2).

147 Based on Eqs. (2)-(4), the volume change of gas during the loading process $\delta V_{g}$ can be 148 calculated as below

$$
\delta V_{g}=V_{g}^{0}-V_{g}^{f}=\frac{f_{0}\left(1+e_{m}^{0}\right)}{1-f_{0}} \frac{1+b \frac{p_{f}^{\prime}}{p_{0}^{\prime}}}{1+\frac{u_{w}^{0}+p_{a}}{p_{0}^{\prime}}+b \frac{p_{f}^{\prime}}{p_{0}^{\prime}}} \quad \text { with } \quad b=\frac{1}{a} M-1
$$

The volume change of the saturated soil matrix during loading $\delta V_{m}$ is

$$
\delta V_{m}=V_{m}^{0}-V_{m}^{f}=(\mathrm{N}-\Gamma)-(\lambda-\kappa) \ln R+\lambda \ln \left(\frac{p_{f}^{\prime}}{p_{0}^{\prime}}\right)
$$

where $\mathrm{N}$ and $\Gamma$ represent the value of $V_{m}$ on the normal consolidation line (NCL) and critical state line (CSL) at unit mean effective stress, respectively (Fig. 2); $\lambda$ is the slope of NCL and CSL in the $V_{m}-\ln p^{\prime}$ plane; $R$ is the degree of overconsolidation at the initial state. For the MCC model, $N-\Gamma=(\lambda-\kappa) \ln 2$, and Eq. (6) can be rewritten as

where $\kappa$ is the slope of the swelling line in the $V_{m}-\ln p^{\prime}$ plane. Based on Assumption (c), one

$$
\delta V_{m}=V_{m}^{0}-V_{m}^{f}=(\lambda-\kappa) \ln \frac{2}{R}+\lambda \ln \left(\frac{p_{f}^{\prime}}{p_{0}^{\prime}}\right)
$$
can get the following based on Eqs. (5) and (7)

$$
\frac{f_{0}\left(1+e_{m}^{0}\right)}{1-f_{0}} \frac{1+b \frac{p_{f}^{\prime}}{p_{0}^{\prime}}}{1+\frac{u_{w}^{0}+p_{a}}{p_{0}^{\prime}}+b \frac{p_{f}^{\prime}}{p_{0}^{\prime}}}-\lambda \ln \left(\frac{p_{f}^{\prime}}{p_{0}^{\prime}}\right)=(\lambda-\kappa) \ln \left(\frac{2}{R}\right)
$$

The undrained shear strength of the saturated soil $s_{u}^{s}$ with $p_{0}^{\prime}$ is (Muir Wood, 1990)

$$
s_{u}^{S}=\frac{1}{2} q_{f}=\frac{1}{2} M p_{0}^{\prime} \Lambda=\frac{1}{2} M p_{0}^{\prime}\left(\frac{R}{2}\right)^{\frac{\lambda-\kappa}{\lambda}}
$$

Based Assumption (d), the upper limit for the undrained shear strength of the unsaturated 163 soil is

$$
s_{u}=\frac{1}{2} M p_{f}^{\prime}
$$


Eq. (8) can thus be expressed in terms of $s_{u}^{s}$ as below based on Eqs. (9) and (10)

$$
\frac{f_{0}\left(1+e_{m}^{0}\right)}{1-f_{0}} \frac{1+\left(\frac{b}{\Lambda}\right) \frac{s_{u}}{s_{u}^{s}}}{1+\frac{u_{w}^{0}+p_{a}}{p_{0}^{\prime}}+\left(\frac{b}{\Lambda}\right) \frac{s_{u}}{s_{u}^{s}}}-\lambda \ln \left(\frac{1}{\Lambda} \frac{s_{u}}{s_{u}^{s}}\right)=(\lambda-\kappa) \ln \left(\frac{2}{R}\right)
$$

While an explicit expression of $\frac{s_{u}}{s_{u}^{s}}$ in terms of $f_{0}$ cannot be obtained using Eq. (11), the value of $f_{0}$ can be easily determined when $\frac{s_{u}}{s_{u}^{s}}$ and other variables are known. Since $\frac{s_{u}}{s_{u}^{s}} \geq 1$ for the upper limit, the relationship between $f_{0}$ and $s_{u}^{s}$ should be generated starting from $\frac{s_{u}}{s_{u}^{s}}=1$ based on Eq. (11). The upper limit expressed by Eq. (11) is dependent on the $\frac{u_{w}^{0}+p_{a}}{p_{0}^{\prime}}$ and total stress path described by the different variable $a$, which is not fully considered by Wheeler (1986). This makes the new upper limit work better for specific loading conditions with different $u_{w}^{0}, p_{0}^{\prime}$ and total stress paths. More discussion on this will be given in the section on the validation using existing test data.

\section{The lower bound}

By treating the saturated soil matrix as a rigid perfectly plastic von Mises-type material, Wheeler et al. (1990) showed that the undrained shear strength of gassy clay can be expressed as

$$
4\left[\frac{3-2 f_{f}^{\frac{1}{4}}}{3\left(1-f_{f}^{\frac{1}{3}}\right)}\right]^{2} s_{u}^{2}+\left(\frac{3}{2 \ln f_{f}}\right)^{2}\left(p_{f}-u_{g}\right)^{2}=4\left(s_{u}^{S}\right)^{2}
$$

where $f_{f}$ is the gas volume fraction at failure (Wheeler, 1986; Green, 1972). The lower bound in Wheeler (1986) was derived by assuming that there is no change in the gas volume and gas pressure during the loading $\left(f_{f}=f_{0}\right.$ and $\left.u_{g}=u_{w}^{0}\right)$. It is shown by Sultan et al. (2012) that the lower limit proposed by Wheeler (1986) does offer an absolute lower bound for the test data. But it can be too conservative for tests in which significant contraction of gas bubbles occurs. The reason is that the assumption of $f_{f}=f_{0}$ can be too conservative when the gas volume decreases during loading, which makes $f_{f}<f_{0}$ and undrained shear strength higher. In this study, the lower limit is derived by considering the gas volume change. The following assumptions are made: 
(a) The stress and strain state in the soil remains uniform but the failure condition can still be expressed by Eq. (12). Note that Eq. (12) was originally derived based on non-uniform stress distribution in the soil;

(b) The initial gas pressure $u_{g}^{0}$ is the same as the initial pore water pressure $u_{w}^{0}$. The same assumption has been used in the lower bound of Wheeler (1986). Gas dissolution in pore water is neglected.

(c) The change of gas pressure $\delta u_{g}$ is the same as the change in total stress $\delta p$. This is based on the Eq. (8) of Wheeler et al. (1990). When the gas volume fraction is assumed constant, that equation gives $\delta u_{g}=\delta p$. The cavity volume is the same as the gas volume in the lower bound case.

In a globally undrained test, the $\delta u_{g}$ for the lower bound can be obtained based on Fig. 2 as below

$$
\delta u_{g}=\delta p=\frac{2}{a} s_{u}^{s}=\frac{1}{a} M p_{0}^{\prime} \Lambda
$$

In this case, the Boyle's law for the gas is expressed as

$$
\left(u_{w}^{0}+p_{a}\right) V_{g}^{0}=\left(u_{w}^{0}+p_{a}+\frac{1}{a} M p_{0}^{\prime} \Lambda\right) V_{g}^{f}
$$

Eq. (14) can be used to get $V_{g}^{f}$ as below

$$
V_{g}^{f}=\frac{u_{w}^{0}+p_{a}}{u_{w}^{0}+p_{a}+\frac{1}{a} M p_{0}^{\prime} \Lambda} V_{g}^{0}=\frac{\frac{u_{w}^{0}+p_{a}}{p_{0}^{\prime}}}{\frac{u_{w}^{0}+p_{a}}{p_{0}^{\prime}}+\frac{1}{a} M \Lambda} \frac{f_{0}}{1-f_{0}} V_{m}^{0}=\beta \frac{f_{0}}{1-f_{0}} V_{m}^{0}
$$

where $\beta$ is self-evident. Since bubble flooding is not considered in the lower bound, $V_{m}^{0}=V_{m}^{f}$ due to the undrained condition. The gas volume fraction at failure $f$ can be expressed as below based on Eqs. (3) and (15)

$$
f_{f}=\frac{V_{g}^{f}}{V_{g}^{f}+V_{m}^{0}}=\frac{\beta \frac{f_{0}}{1-f_{0}}}{\beta \frac{f_{0}}{1-f_{0}}+1}=\frac{\beta f_{0}}{1+(\beta-1) f_{0}}
$$

Since $u_{g}^{0}=u_{w}^{0}$ and $\delta u_{g}=\delta p$ (Assumptions $\mathrm{b}$ and $\mathrm{c}$ above), one can get $p_{f}-u_{g}=p_{0}^{\prime}$. Therefore, the new lower bound is expressed as 


$$
4\left[\frac{3-2 f_{f}^{\frac{1}{4}}}{3\left(1-f_{f}^{\frac{1}{3}}\right)}\right]^{2} s_{u}^{2}+\left(\frac{3}{2 \ln f_{f}}\right)^{2}\left(p_{0}^{\prime}\right)^{2}=4\left(s_{u}^{s}\right)^{2}
$$

213 with $s_{u}^{s}$ and $f_{f}$ being expressed by Eqs. (9) and (16), respectively. Similar to the new upper

214 bound, the new lower bound is also dependent on $\frac{u_{w}^{0}+p_{a}}{p_{0}^{\prime}}$ and total stress path which is 215 described by the variable $a$ (Fig. 2).

217 Validation of the new lower and upper bounds

218 The prediction of the new lower and upper bounds will be compared with the test data on 219 three gassy clays. The MCC model parameters for these clays are shown in Table 1 . All the 220 tests have been done under undrained triaxial compression condition with $\delta q=3 \delta p(a=3$ 221 in Fig. 2). Most of the samples are normally consolidated and some are lightly overconsolidated. The $s_{u}^{s}$ is calculated in different ways for the new and Wheeler's bounds. Eq. (9) is used to determine $s_{u}^{s}$ for the new bounds. To make it consistent with the work by Wheeler (1986), the $s_{u}^{s}$ for Wheeler's (1986) bounds is taken as the measured undrained 225 shear strength for saturated clays.

\section{Combwich mud with methane (Wheeler, 1986)}

Figs. 3-4 show the prediction of the new upper and lower bounds with the test data on normally consolidated gassy Combwich mud (Wheeler, 1986). The prediction of Wheeler's theory is also included. In most cases, the new upper and lower bounds are closer to the test data. The prediction of the new upper bound is lower than the one in Wheeler (1986) because the new theory does not assume complete bubble flooding. The prediction of the new lower bound is slightly higher than the lower bound of Wheeler (1986). This is due to that the new lower bound considers gas bubble contraction during loading, which makes the undrained shear strength higher.

235 At the same $f_{0}$, the new theory predicts lower shear strength for both the lower and upper

236 bounds as $\frac{u_{w}^{0}+p_{a}}{p_{0}^{\prime}}$ increases (Fig. 4). This agrees with the test data, which shows that $s_{u}$ 237 decreases when $\frac{u_{w}^{0}+p_{a}}{p_{0}^{\prime}}$ increases at the same $f_{0}$. The reasons are: (a) For the new upper 
238 bound, higher $\frac{u_{w}^{0}+p_{a}}{p_{0}^{\prime}}$ makes the amount of bubble flooding smaller and undrained shear

239 strength smaller (Eq. 5); (b) In the new lower bound, higher $\frac{u_{w}^{0}+p_{a}}{p_{0}^{\prime}}$ renders the bubble 240 contraction smaller and $f_{f}$ bigger at the same $f_{0}$, leading to smaller $s_{u}$ (Eqs. 15 and 16).

241 For the tests with $p_{0}^{\prime}=200 \mathrm{kPa}$ and $u_{w}^{0}=100 \mathrm{kPa}$, it appears that the new lower bond tends 242 to overestimate the undrained shear strength, while Wheeler's does better. This indicates 243 that the new lower bound may overpredict the undrained shear strength of gassy clay under 244 certain loading conditions. This overprediction is mainly caused by the Assumption (a) for the 245 new lower bound which neglects the nonuniform stress distribution in gassy clay that has a 246 negative effect on the soil strength.

\section{Kaolin with helium (Sham, 1989)}

248 Figs. 5-6 show the comparison between the test data and theoretical predictions for normally 249 consolidated Kaolin with helium (Sham, 1989). The gas bubbles are found to have primarily detrimental effect on the undrained shear strength. The upper bound of Wheeler (1986) gives much higher $s_{u}$ than the new upper bound, with the latter offering better prediction of the maximum possible $s_{u}$ for unsaturated soils (Figs. 5a and 6a). At the same $p_{0}^{\prime}$ and $f_{0}$, the new upper bound gives lower $s_{u}$ for unsaturated soils as $u_{w}^{0}$ increases. This is due to smaller amount of bubble flooding at higher $u_{w}^{0}$ or $u_{g}^{0}$ (Eq. 5). Wheeler's lower bound predicts zero $s_{u}$ at $f_{0}$ between 0.03 and 0.04 , which appears to be very conservative. The new lower bound gives zero $s_{u}$ at higher $f_{0}$ for all the tests, as it considers gas cavity compression during loading. This is closer to the test data. But it is still conservative for tests with $f_{0}>0.2$ (Figs. $5 \mathrm{~b}$ and $6 \mathrm{~b})$. There could be much more gas cavity compression at higher $f_{0}$ in real soil samples than that assumed in Eqs. (13) and (14).

Fig. 7 shows the results of overconsolidated Kaolin with $R=2$. Both the new and Wheeler's (1986) lower bounds give higher $s_{u}$ than the measured value when $f_{0}>0.01$. But the Wheeler's is closer to the test data. One possible reason is that gas bubble expansion during isotropic unloading which was used to create overconsolidated samples has caused irreversible damage to the soil structure (Sultan et al., 2012). The new lower bound does not consider this damage. Meanwhile, it accounts for the bubble compression in triaxial compression after the isotropic unloading, which has beneficial effect on $s_{u}$. This makes the 
new lower bound prediction higher. Similar to the normally consolidated samples, the new upper bound gives smaller $s_{u}$ than the Wheeler's.

\section{Malaysian Kaolin silt with nitrogen (Hong et al. 2020)}

Fig. 8 shows the test results of normally consolidated Malaysian Kaolin silt with different $u_{w}^{0}$ (Hong et al. 2020). $p_{0}^{\prime}$ is $200 \mathrm{kPa}$ for all the tests. All the test results lie in the new upper and lower bounds. The new bounds are closer to the test data than the Wheeler's. The results of tests with $u_{w}^{0}=0$ and $u_{w}^{0}=50 \mathrm{kPa}$ lie exactly on the new upper bound, while the test results for $u_{w}^{0}=600 \mathrm{kPa}$ are very close to the new lower bound. Compared to the other two clays above, the gas bubbles are found to have less detrimental effect on $s_{u}$. Hong et al. (2020) have shown that this is related to the plastic index $\left(I_{p}\right)$ of clays. The Malaysian kaolin silt has the lowest $I_{p}$ and the least detrimental effect can be observed. The most significant detrimental effect can be seen on Kaolin reported in Sham (1989) which has the highest $I_{p}$.

Fig. 9 shows the results of lightly overconsolidated Malaysian kaolin with different $u_{w}^{0}$ (Hong et al., 2020). All the samples were first consolidated to $p_{c}^{\prime}=200 \mathrm{kPa}$ and then unloaded to different $p_{0}^{\prime}=p_{c}^{\prime} / R$. The overconsolidation ratio $R$ varies between 1.05 and 1.67. The undrained shear strength is normalized by the $s_{u}^{S}$ at $R=1$. For each test, the initial gas volume fraction $f_{0}$ is different, which can be found in Hong et al. (2020). Some of the test data is above the new upper bound at $u_{w}^{0}=0$, which means that there could be more bubble flooding than the theoretical prediction. At $u_{w}^{0}=600 \mathrm{kPa}$, the lower bound is higher than the measured results at $R=1.43$ and $R=1.67$. Similar to the case for overconsolidated Kaolin in Sham (1989), there could be irreversible soil structure damage during isotropic unloading, which is not accounted for by the new lower bound.

\section{Effect of total stress path}

The pore water pressure $u_{w}$ is found to have dramatic influence on the behaviour of gassy clay (Wheeler, 1986; Sham, 1989; Hong et al., 2017). Under otherwise identical conditions of $f_{0}$ and $R$, gassy clay has smaller $s_{u}$ at higher $u_{w}$. It is important to realize that $u_{w}$ changes during loading. In undrained tests, the evolution of $u_{w}$ is dependent on the total stress path, which means that the $s_{u}$ of gassy clay is affected by the total stress path (Sultan et al., 2012). The upper and lower bounds of Wheeler (1986) are independent of the total stress path. Fig. 10 shows the prediction of the new upper and lower bounds under total stress paths with 
different $a$ values (Fig. 2). The parameters for Combwich mud are used and the soil is assumed to be normally consolidated. When $a=\infty$, the total stress path is $\delta p=0$. As $a$ increases from 3 to $\infty$, both the new upper and lower bounds give smaller $s_{u}$. Smaller $a$ leads to smaller change in $u_{w}$ (Fig. 2), which means less bubble flooding and lower $s_{u}$ for the upper bound. For the lower bound, bigger $a$ causes less bubble compression and higher $f_{f}$ at the same $f_{0}$, which makes the $s_{u}$ smaller. When $a<0$, the $s_{u}$ predicted by the new lower bound is smaller than that of Wheeler's because it considers gas bubble expansion due to reduction in $p$ (Eqs. 13-15). When the absolute value of negative $a$ is sufficiently large, $u_{w}$ can decrease during loading, indicating that there can be 'negative' bubble flooding based on Eqs. (2)-(7), which is water flow from a partially flooded bubble to the saturated matrix. But there is no experimental evidence to show if there is 'negative' bubble flooding at present. For all the simulations presented here, $u_{w}$ increases and 'negative' bubble flooding does not occur. Unfortunately, there is no test data under loading conditions with $a=\infty$ and $a<0$. Future experimental work will be done on gassy under different total stress paths to validate the new upper and lower bounds.

\section{Discussion on the interaction between gas bubbles and saturated soil matrix}

The upper and lower bounds of Wheeler (1986) give the maximum and minimum possible $s_{u}$ for gassy clays, respectively. They are found to work for all the clays above. The new bounds are generally closer to the test data because complete bubble flooding is not assumed for the upper bound and gas volume change during loading is considered for the lower limit. The new bounds are also dependent on the stress path. Therefore, the new bounds can be used to get better prediction of $s_{u}$ for specific loading conditions.

Some of the test data is very close to the new upper or lower bound, indicating that either bubble flooding or the detrimental effect dominates. But most of the results are within the two bounds. For these tests, some of the gas cavities degrade the soil structure and reduces the undrained shear strength. Meanwhile, some of the bubbles may get flooded by pore water from the saturated matrix, which has beneficial effect on the soil stiffness and strength. As a result, the $s_{u}$ measured for the entire soil sample lie within the two bounds. The $s_{u}$ measured for gassy clay is also dependent on $\frac{u_{w}^{0}+p_{a}}{p_{0}^{\prime}}$. 
This has important implications for constitutive modelling of gassy clays. First, the theoretical predictions above show that gassy clay is a composite material with a saturated soil matrix and compressible gas cavities. These bubbles tend to damage the soil structure but could be flooded by pore water. The condition for bubble flooding is $u_{g} \approx u_{w}$ for each gas bubble (Wheeler, 1988). For the entire soil, however, some bubbles are flooded while others are not, depending on the microstructure of cavity surface (Wheeler et al., 1990). Complete bubble flooding does not occur, as the measured $s_{u}$ is well below Wheeler's upper bound. Besides, the variable $\frac{u_{w}^{0}+p_{a}}{p_{0}^{\prime}}$ is appropriate for modelling the effect of free gas on mechanical behaviour

334 of gassy clay. Higher $\frac{u_{w}^{0}+p_{a}}{p_{0}^{\prime}}$ leads to less bubble flooding and more detrimental effect (Hong 335 et al., 2020; Gao et al., 2020). Note that the variable $\frac{u_{g}^{0}+p_{a}}{p_{0}^{\prime}}$ has been used for gassy clay, but it is very difficult to measure $u_{g}$ (Wheeler, 1986; Sham, 1989; Gao et al., 2020).

\section{Conclusion}

338 New lower and upper bounds for the undrained shear strength of gassy clay have been developed based on the critical state soil mechanics and original work of Wheeler (1986). The new upper bound is derived based on the assumption that the gas volume change is the same as the amount of pore water flow into the cavities. The MCC model is used to calculate the undrained shear strength after bubble flooding. The lower limit is derived based on the original work of Wheeler (1986) by considering the gas volume change during loading.

Both the new and Wheeler's (1986) lower and upper bounds are capable of describing the undrained shear strength of gassy clay but the new bounds are closer to the test data of three gassy clays. Therefore, Wheeler's bounds predict the possible maximum and minimum undrained shear strength for all loading conditions, but the new bounds work better for predicting the undrained shear strength under specific loading conditions. The new bounds can also account the effect of total stress path on the undrained shear strength of unsaturated samples. But more experimental work needs to be done to verify the predictions. The new lower bound is found to overestimate the undrained shear strength of lightly overconsolidated gassy clay. This could be due to that it does not account for the soil structure damaged caused by gas bubble expansion during unloading (Sultan et al., 2012). 
354 This study has several implications for constitutive modelling of gassy clays. The theoretical 355 study shows that the gassy clay has a unique structure with a saturated soil matrix and 356 compressible cavities. Bubbles degrade the soil structure but there could be bubble flooding 357 which increases the soil strength. The variable $\frac{u_{w}^{0}+p_{a}}{p_{0}^{\prime}}$ is proper for characterising the effect of 358 gas on the soil behaviour. Bigger $\frac{u_{w}^{0}+p_{a}}{p_{0}^{\prime}}$ leads to less bubble flooding and more detrimental 359 effect.

360 List of symbols

$\begin{array}{ll}e_{m}^{0} & \text { Initial void ratio for the saturated soil matrix } \\ f & \text { Volume fraction of gas } \\ f_{0} & \text { Initial volume fraction of gas } \\ f_{f} & \text { Gas volume fraction at failure } \\ p & \text { Total stress } \\ p^{\prime} & \text { Mean effective stress } \\ p_{0}^{\prime} & \text { Initial mean effective stress } \\ p_{f}^{\prime} & \text { Mean effective stress at failure } \\ p_{a} & \text { Atmospheric pressure } \\ q & \text { Deviator stress } \\ q_{f} & \text { Deviator stress at failure } \\ s_{u} & \text { Undrained shear strength } \\ s_{u}^{s} & \text { Undrained shear strength of the saturated soil } \\ u_{g} & \text { Initial gas pressure } \\ u_{g}^{0} & \text { Initial gas pressure } \\ u_{w} & \text { Pore water pressure } \\ u_{w}^{0} & u_{w}^{f}\end{array}$




$\begin{array}{ll}V_{m}^{0} & \text { The initial specific volume of the saturated soil matrix } \\ V_{m}^{f} & \text { Specific volume of the saturated soil matrix at failure } \\ V_{g} & \text { Specific volume of free gas } \\ V_{g}^{0} & \text { The initial specific volume of free gas } \\ V_{g}^{f} & \text { Specific volume of gas at failure } \\ \lambda & \text { Slope of normal consolidation line } \\ \kappa & \text { Slope of swelling line } \\ \mathrm{M} & \text { Critical state stress ratio } \\ \mathrm{N} & \text { Value of } V_{m} \text { at unit mean effective stress for the normal } \\ \Gamma & \text { compression line in the } V_{m}-\ln p^{\prime} \text { space } \\ R & \text { Value of } V_{m} \text { at unit mean effective stress for the critical state } \\ a & \text { line in the } V_{m}-\ln p^{\prime} \text { space } \\ & \text { Overconsolidation ratio }\end{array}$

Data availability

Some or all data, models, or code that support the findings of this study are available from the corresponding author upon reasonable request.

\section{Acknowledgement}

365 The authors would like to acknowledge the comments given by Professor Simon Wheeler at 366 the University of Glasgow during our discussions with him.

\section{References}

368

Gao Z, Hong Y, Wang L. 2020. "Constitutive modelling of fine-grained gassy soil: A composite approach. Numerical and Analytical Methods in Geomechnics"44:1350-1368. https://doi.org/10.1002/nag.3065

Green, R.J. 1972. "A plasticity theory for porous solids." International Journal of Mechanical Sciences.14(4):214-224. https://doi.org/10.1016/0020-7403(72)90063-X

Grozic JLH, Nadim F, Kvalstad TJ. 2005. “On the undrained shear strength of fine-grained gassy 
soils." Computers and Geotechnics. 32(7): 483-490. https://doi.org/10.1016/j. compgeo.2005.10.002

Hong Y, Wang LZ, Ng CW, Yang B. 2017. "Effect of initial pore pressure on undrained shear behaviour of fine-grained gassy soil." Canadian Geotechnical Journal. 54(11): 1592-1600. https://doi.org/10.1139/cgj-2017-0015.

Hong Y, Wang LZ, Zhang JF, Gao ZW. 2020. "3D elastoplastic model for fine-grained gassy soil considering the gas-dependent yield surface shape and stress-dilatancy." Journal of Engineering Mechanics. 146(5): 04020037. https://doi.org/10.1061/(asce)em.19437889. 0001760.

Jommi C, Muraro S, Trivellato E, Zwaneburg C. 2019. "Experimental results on the influence of gas on the mechanical response of peats." Géotechnique. 69(9):753-766. https://doi.org/10.1680/jgeot.17.p.148.

Hight, D. W. \& Leroueil, S. 2003. "Characterisation of soils for engineering purposes." In Characterisation and engineering properties of natural soils (eds T. S Tan, K. K. Phoon, D. W. Hight and S. Leroueil), pp. 255-362. Lisse, the Netherlands: Balkema.

Muir Wood D. 1990. "Critical state soil mechanics." Cambridge University Press, Cambridge, UK.

Pietruszczak S, Pande GN. 1996. "Constitutive relationships for partially saturated soils containing gas inclusions." Journal of Engineering Mechanics. 122(1): 50-59. https://doi.org/10.1061/(ASCE)0733-9410(1996)122:1(50).

Roscoe KH, Burland JB. 1968. "On the generalized stress-strain behaviour of 'wet' clay. “Engineering plasticity (eds. J. Heyman and F. A. Leckie), Cambridge University Press, Cambridge, UK, 535-609.

Sham WK. 1989. "The undrained shear strength of soils containing large gas bubbles." PhD thesis, The Queen's University of Belfast.

Sills GC, Wheeler SJ. 1992. "The significance of gas from offshore operations." Continental Shelf Research. 12(10): 1239-1250. https://doi.org/10.1016/0278-4343(92)90083-v. 
401 Sills GC, Wheeler SJ, Thomas SD, Gardner TN. 1991. "Behaviour of offshore soils containing 402 gas bubbles." Géotechnique. 41(2): 227-241. https://doi.org/10.1680/geot.1991.41. $403 \quad 2.227$.

404 Sultan N, De Gennaro V, Puech A. 2012. "Mechanical behavior of gas-charged marine plastic 405 sediments." Géotechnique. 62(9): 751-766. https://doi.org/10.1680/geot.12.og.002.

406 Sultan N, Garziglia S. 2014. "Mechanical behaviour of gas-charged fine sediments: model 407 formulation and calibration." Géotechnique. 64(11): 851-864. https://doi.org/10.1680/ $408 \quad$ geot.13.p.125.

409

Thomas SD. 1987. "The consolidation behaviour of gassy soil." PhD thesis, Oxford University.

Wheeler SJ, Gardner TN. 1989. "Elastic-moduli of soils containing large gas-bubbles." Géotechnique. 39(2): 333-342. https://doi.org/10.1680/geot.1989.39.2.333.

Wheeler SJ. 1986. "The stress-strain behaviour of soils containing gas bubbles." PhD thesis, Oxford University.

Wheeler SJ. 1988a. "A conceptual model for soils containing large gas bubbles." Géotechnique. 38(3): 389-397. https://doi.org/10.1680/geot.1988.38.3.389.

Wheeler SJ. 1988b. "The undrained shear strength of soils containing large gas bubbles." Géotechnique. 38(3):399-413. https://doi.org/10.1680/geot.1988.38.3.399. Canadian Geotechnical Journal. 27(1): 79-89. https://doi.org/10.1139/t90-008. 
Table 1 MCC model parameters

\begin{tabular}{ccccc}
\hline Soil & $M$ & $\lambda$ & $\kappa$ & $\mathrm{N}$ \\
\hline Kaolin with helium & 0.89 & 0.23 & 0.05 & 3.35 \\
Combwich mud with methane & 1.33 & 0.174 & 0.0297 & 3.062 \\
Malaysian kaolin with nitrogen & 1.05 & 0.24 & 0.05 & 3.74 \\
\hline
\end{tabular}




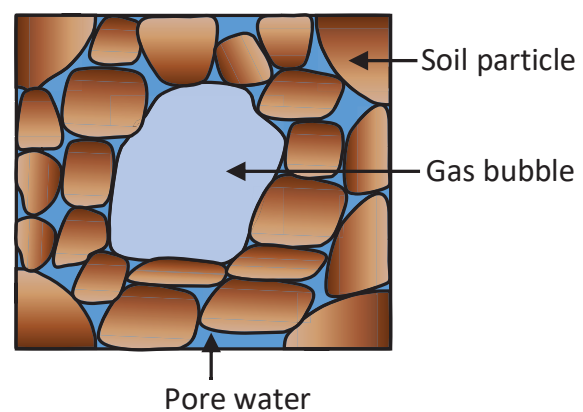

(a)

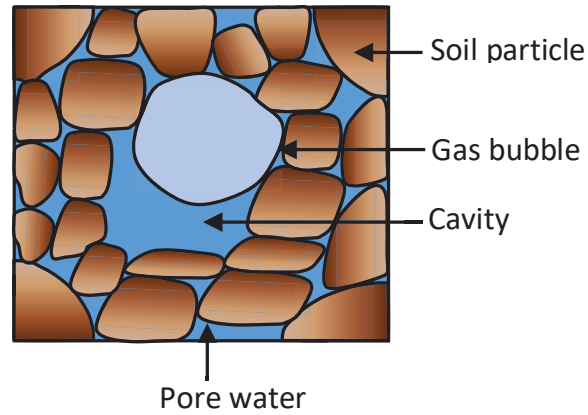

(b)

Fig. 1 A gas bubble in a fine-grained gassy soil: (a) size of the bubble is the same as the cavity; (b) both pore water and gas bubble in a cavity 


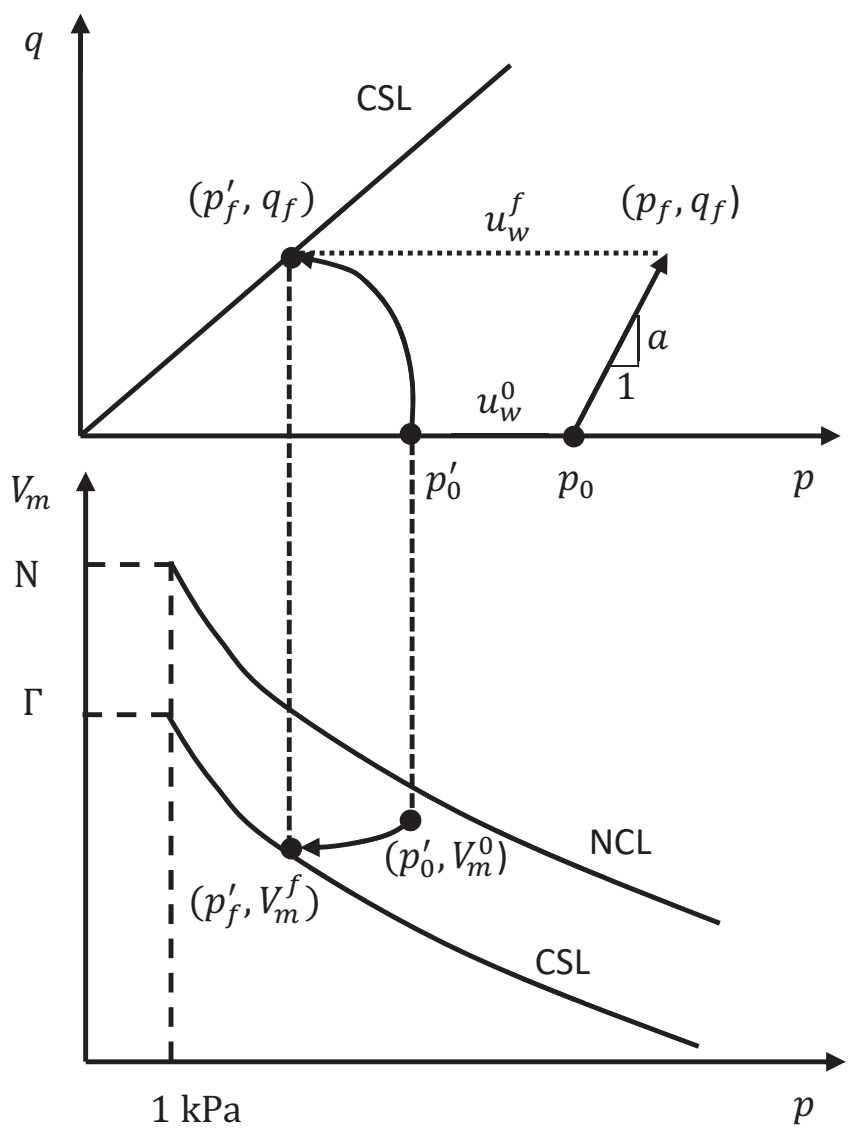

Fig. 2 The initial state, failure state and stress paths for the saturated soil matrix 


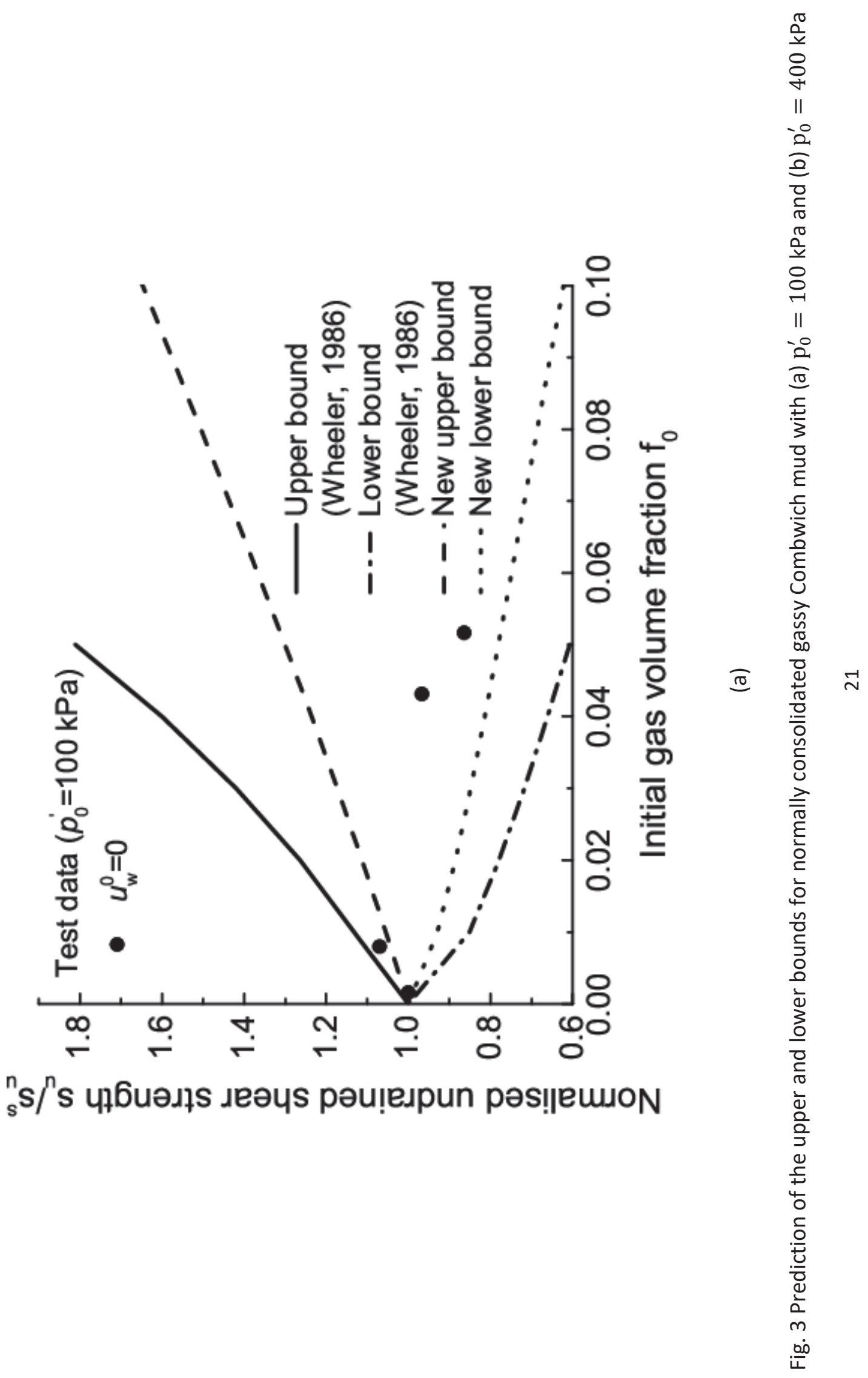




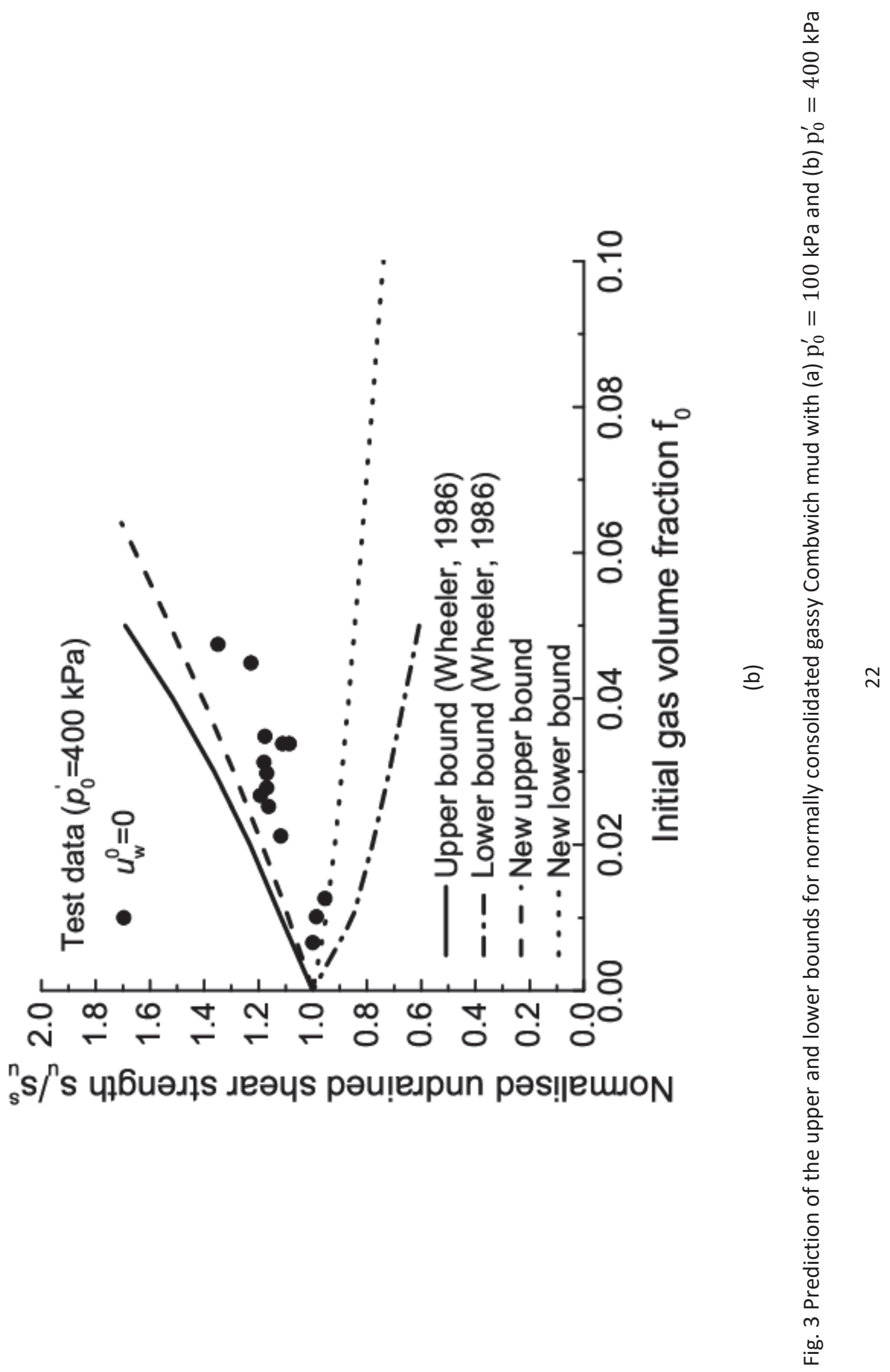



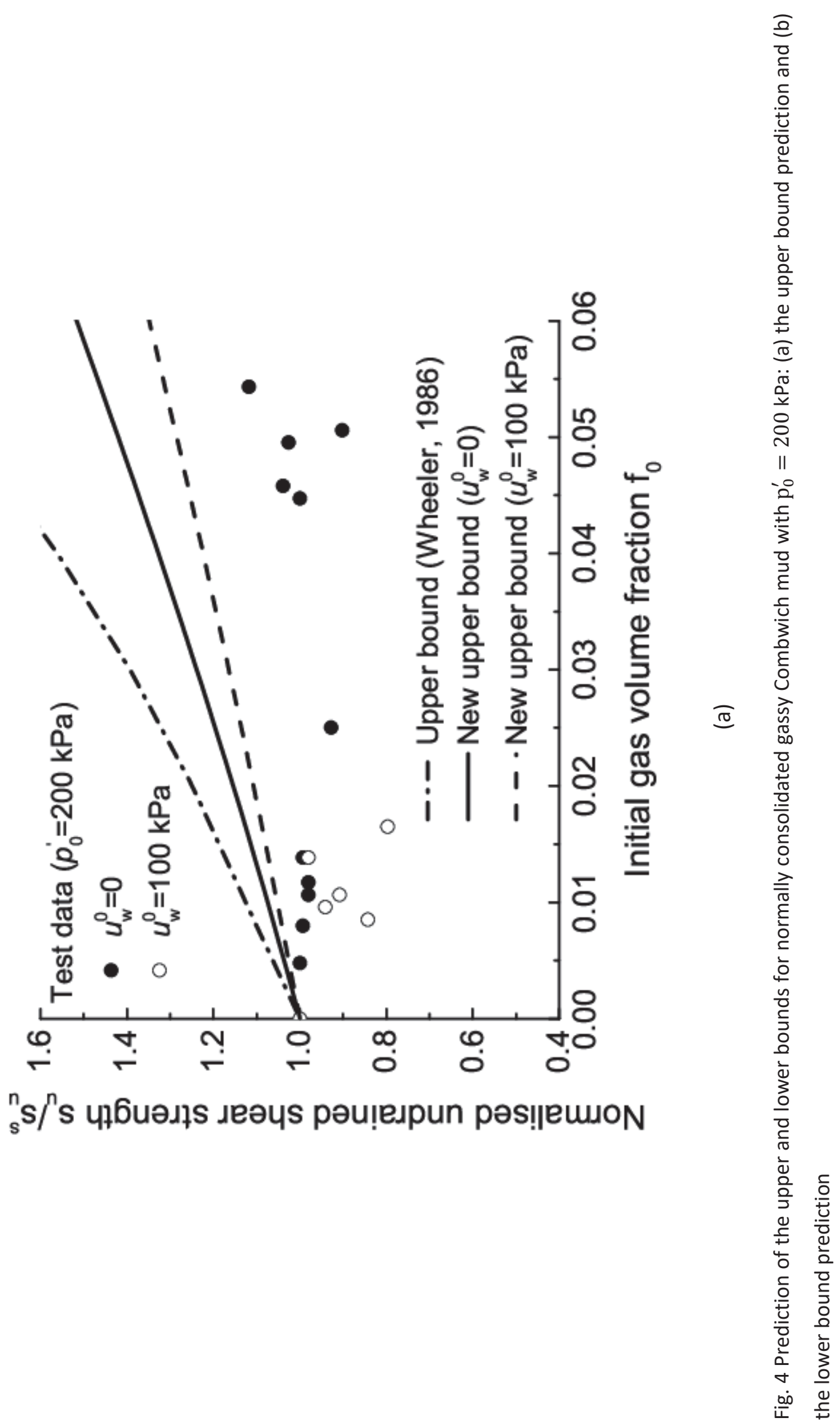

ฟ 

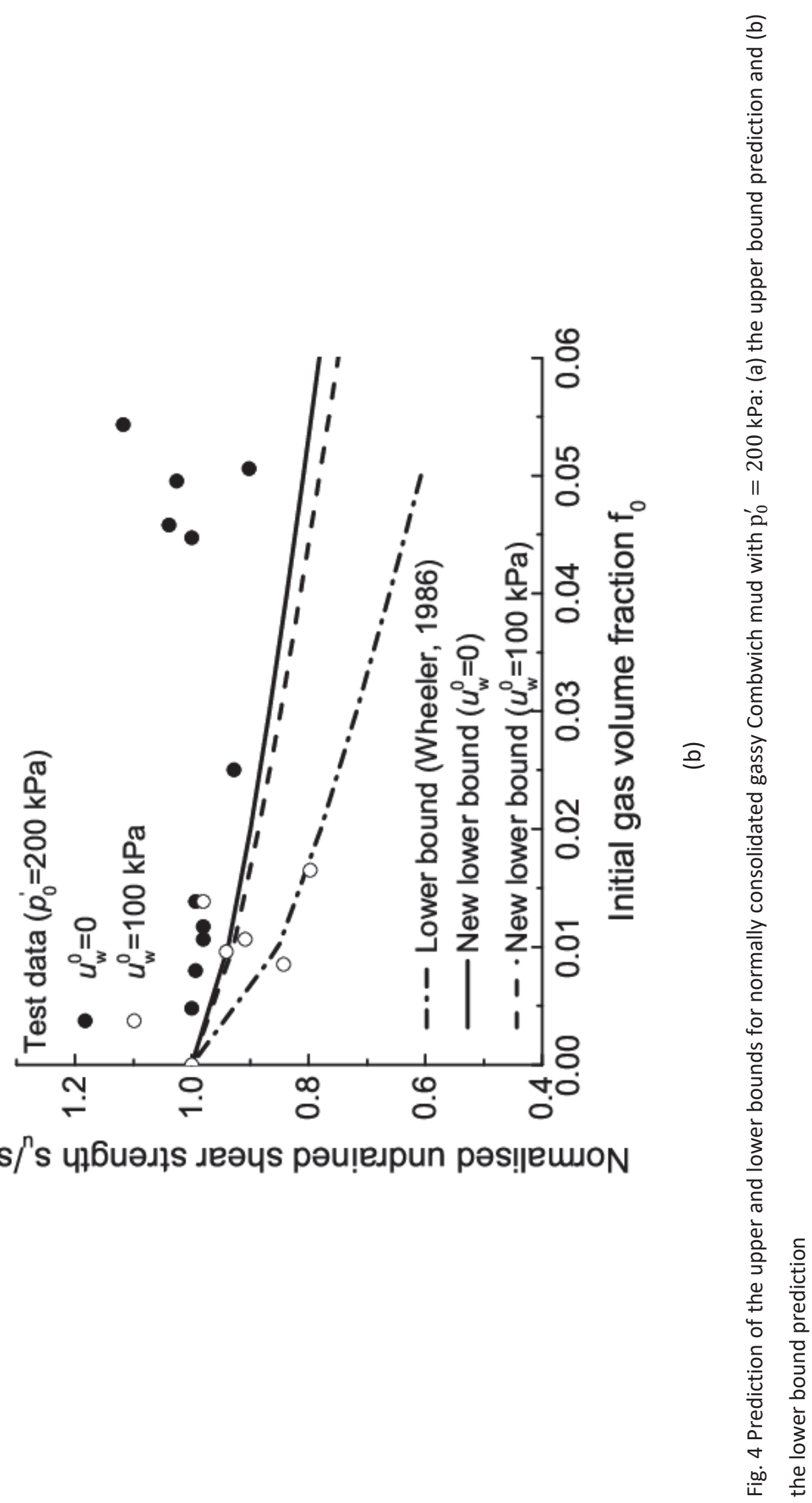

む 


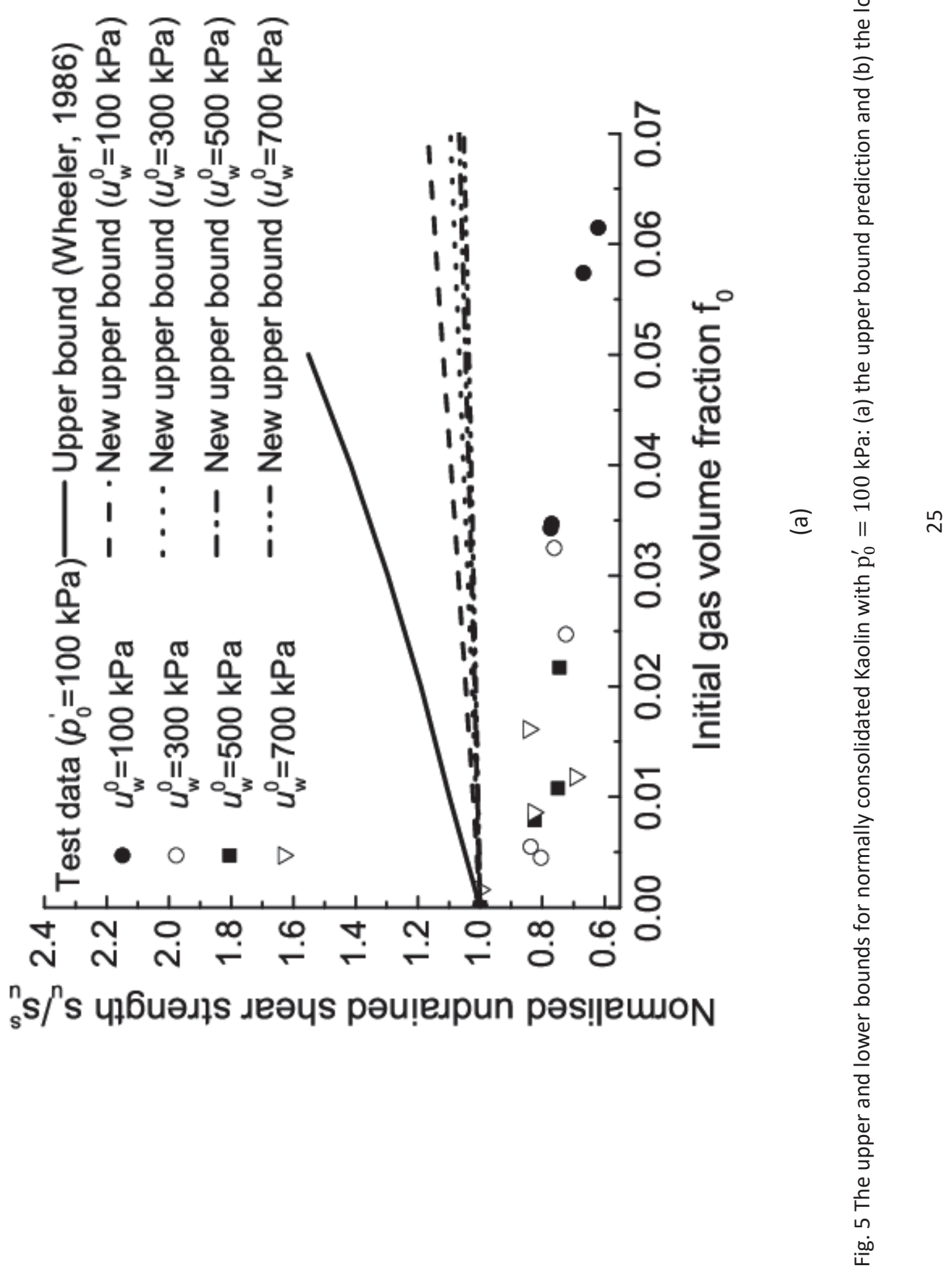




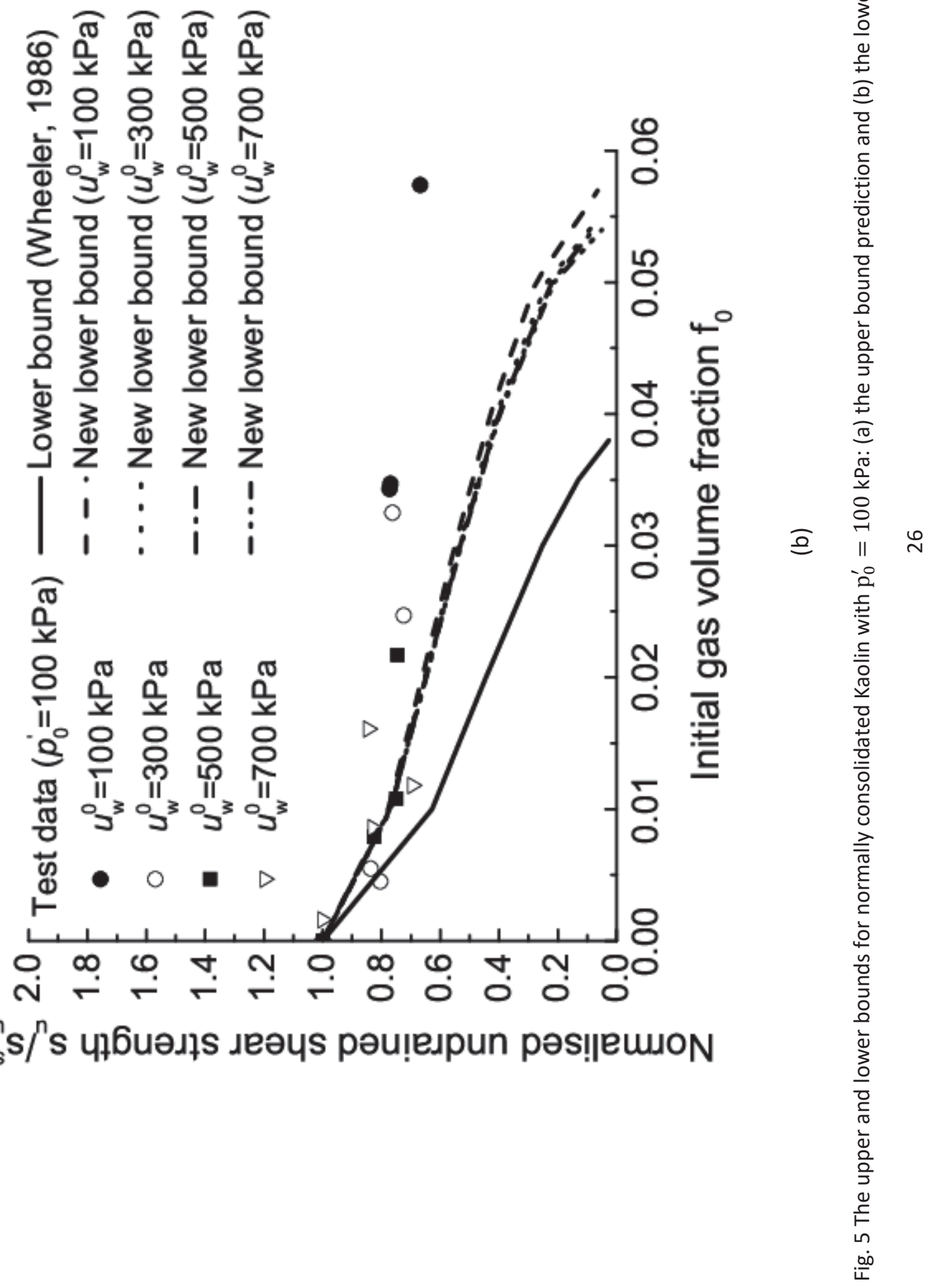




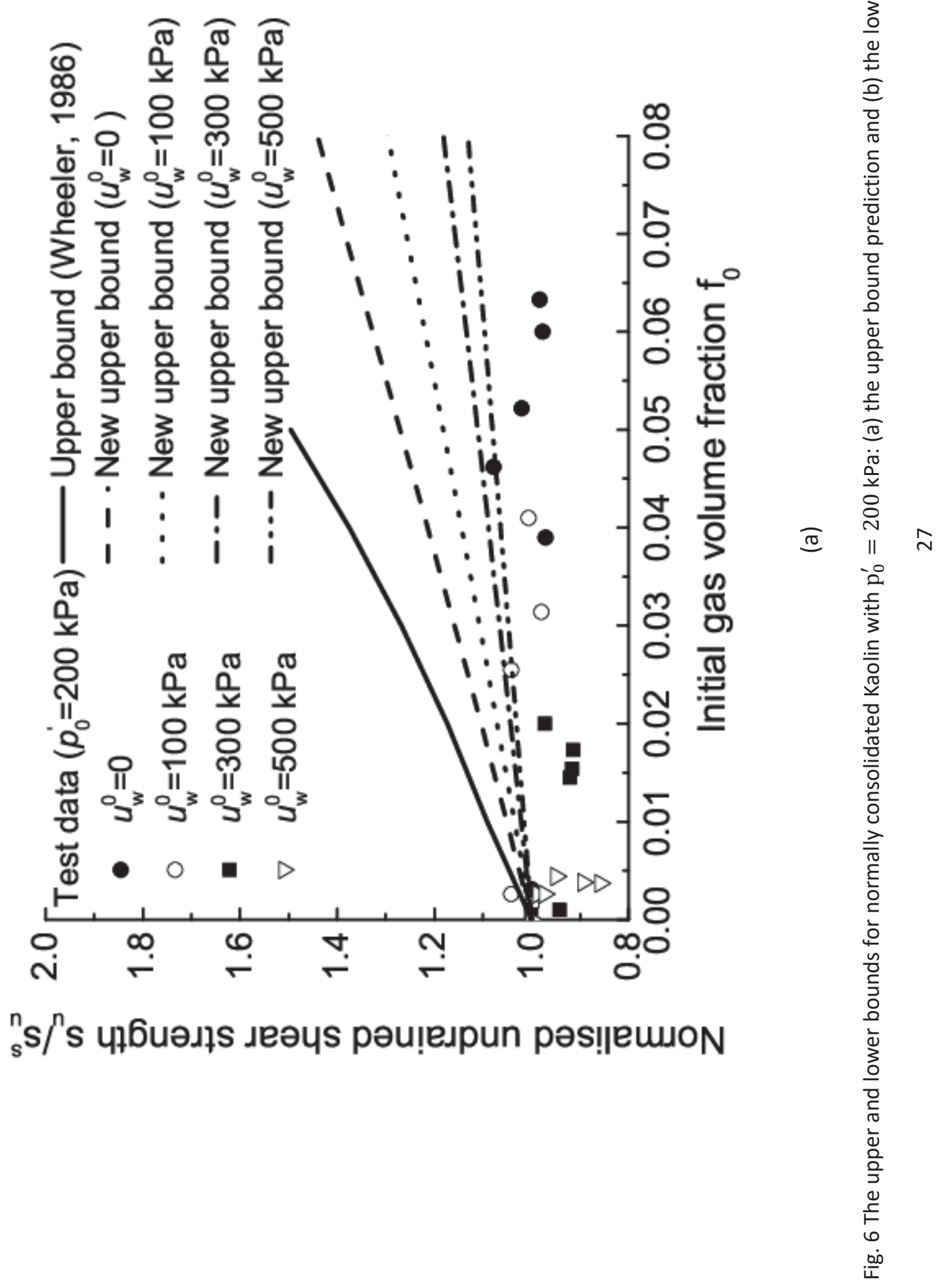




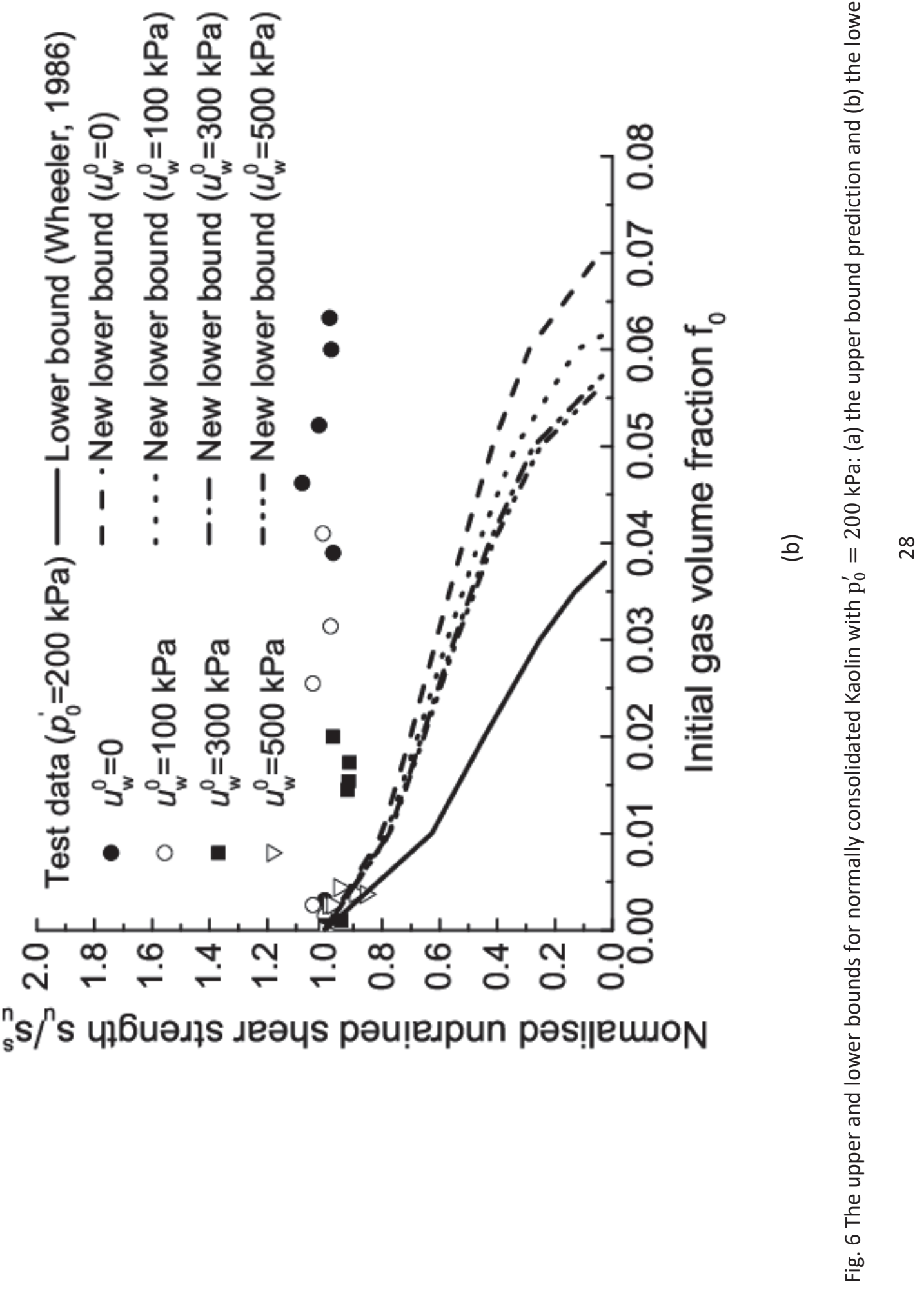




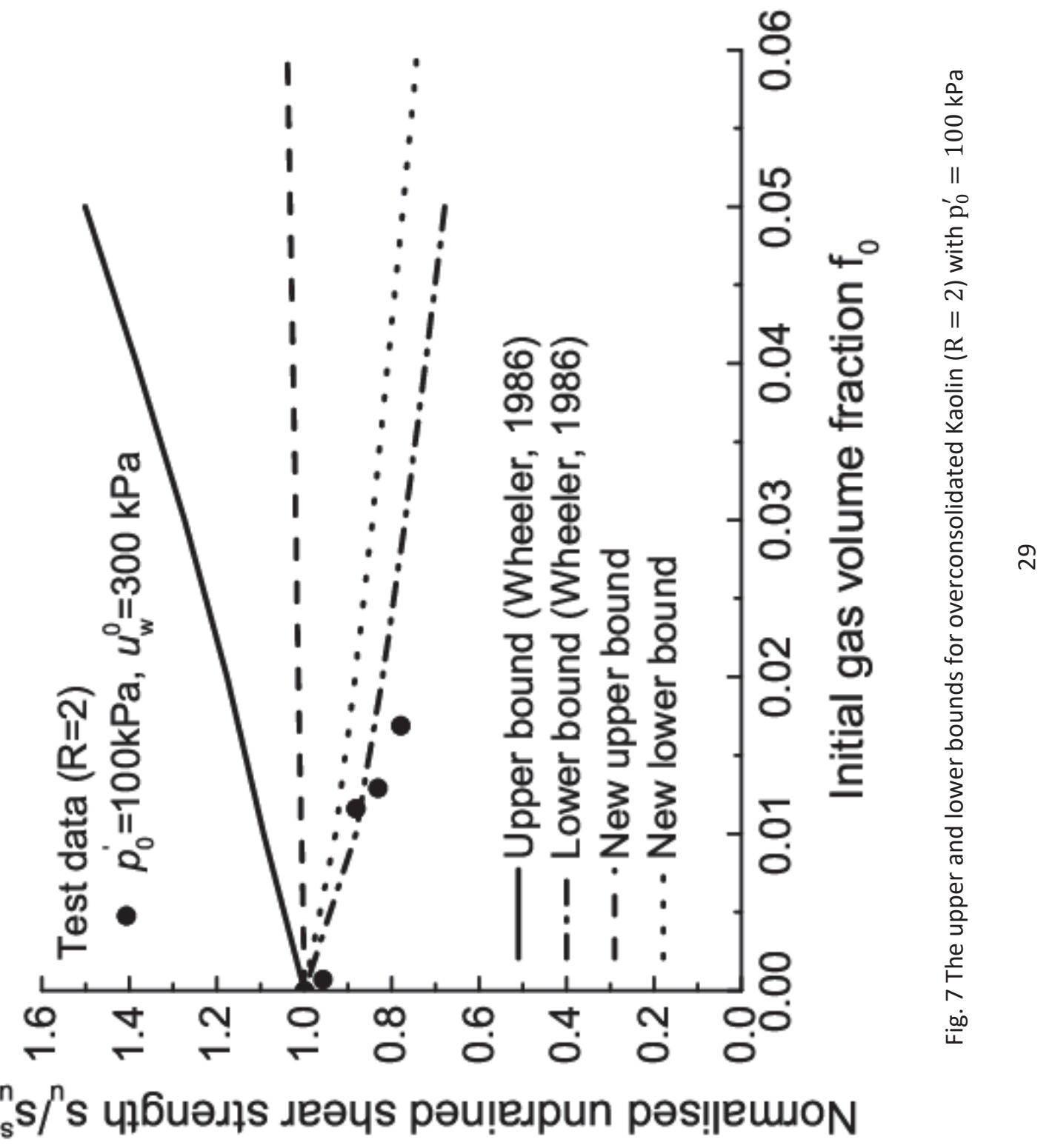




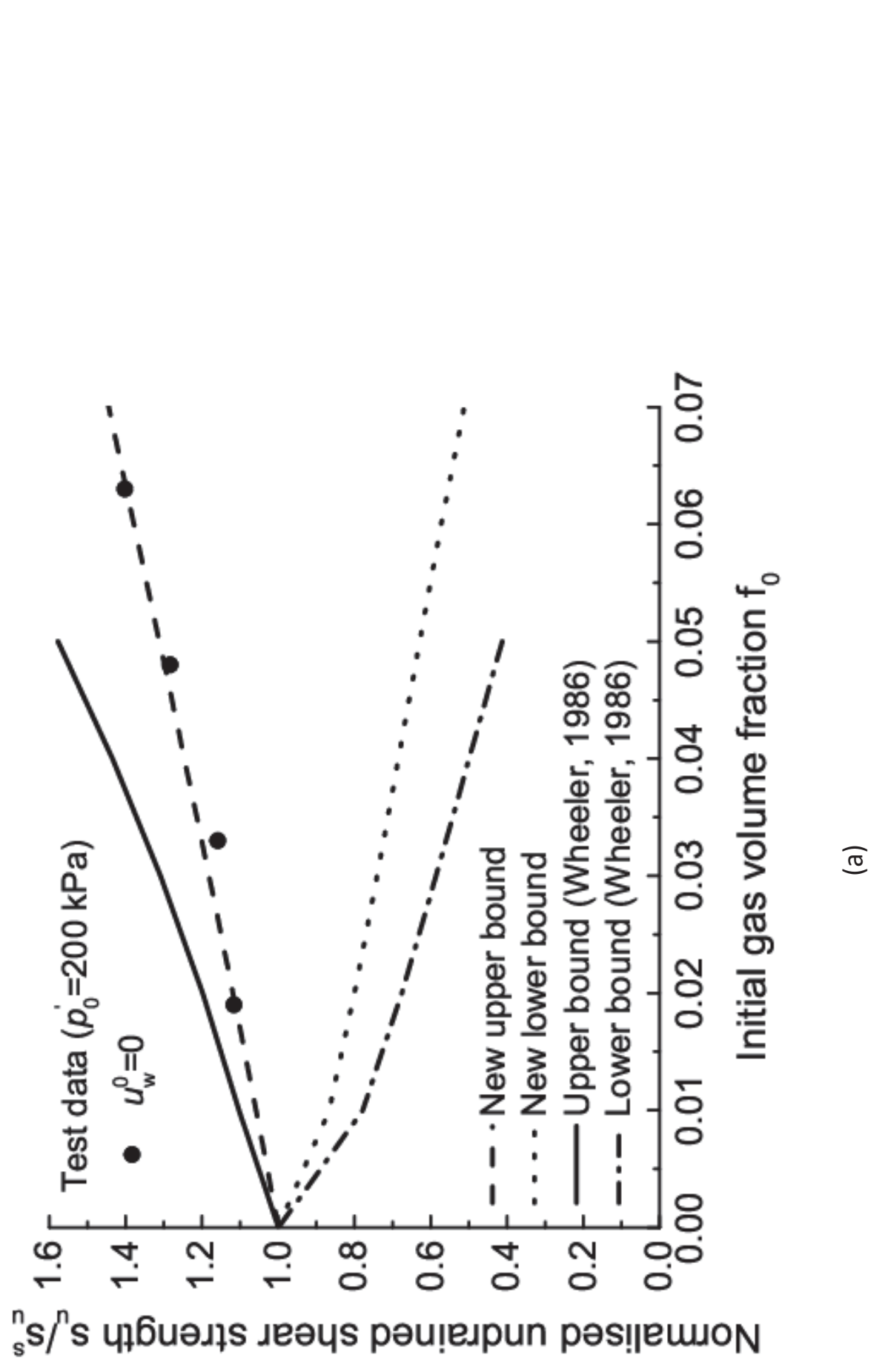

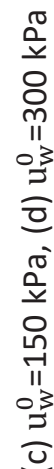

章

II

올

ㅇ

$\stackrel{0}{\frac{\pi}{3}}$

ํำ

․ㅡㄷ

芧

듬

m 


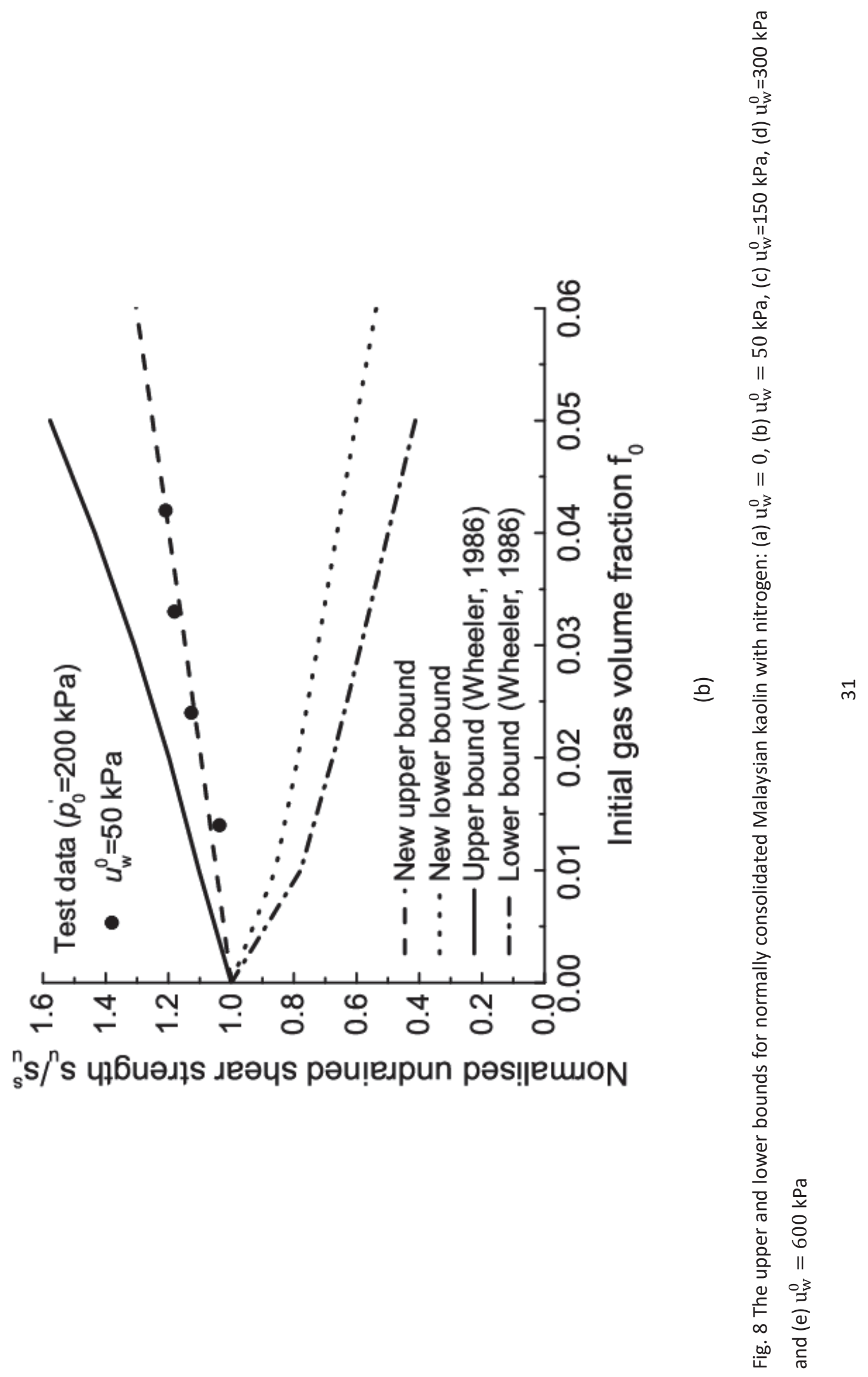




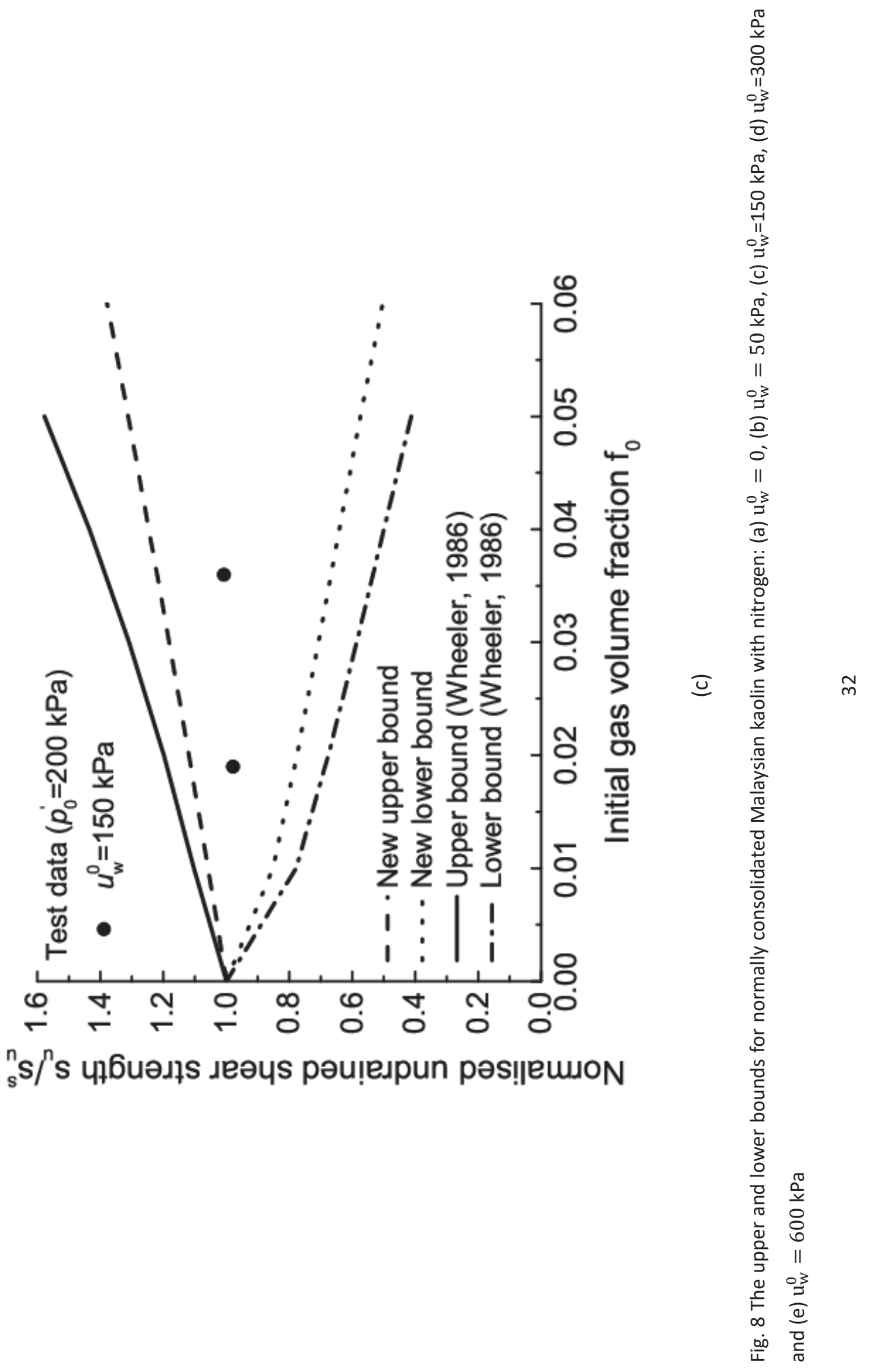




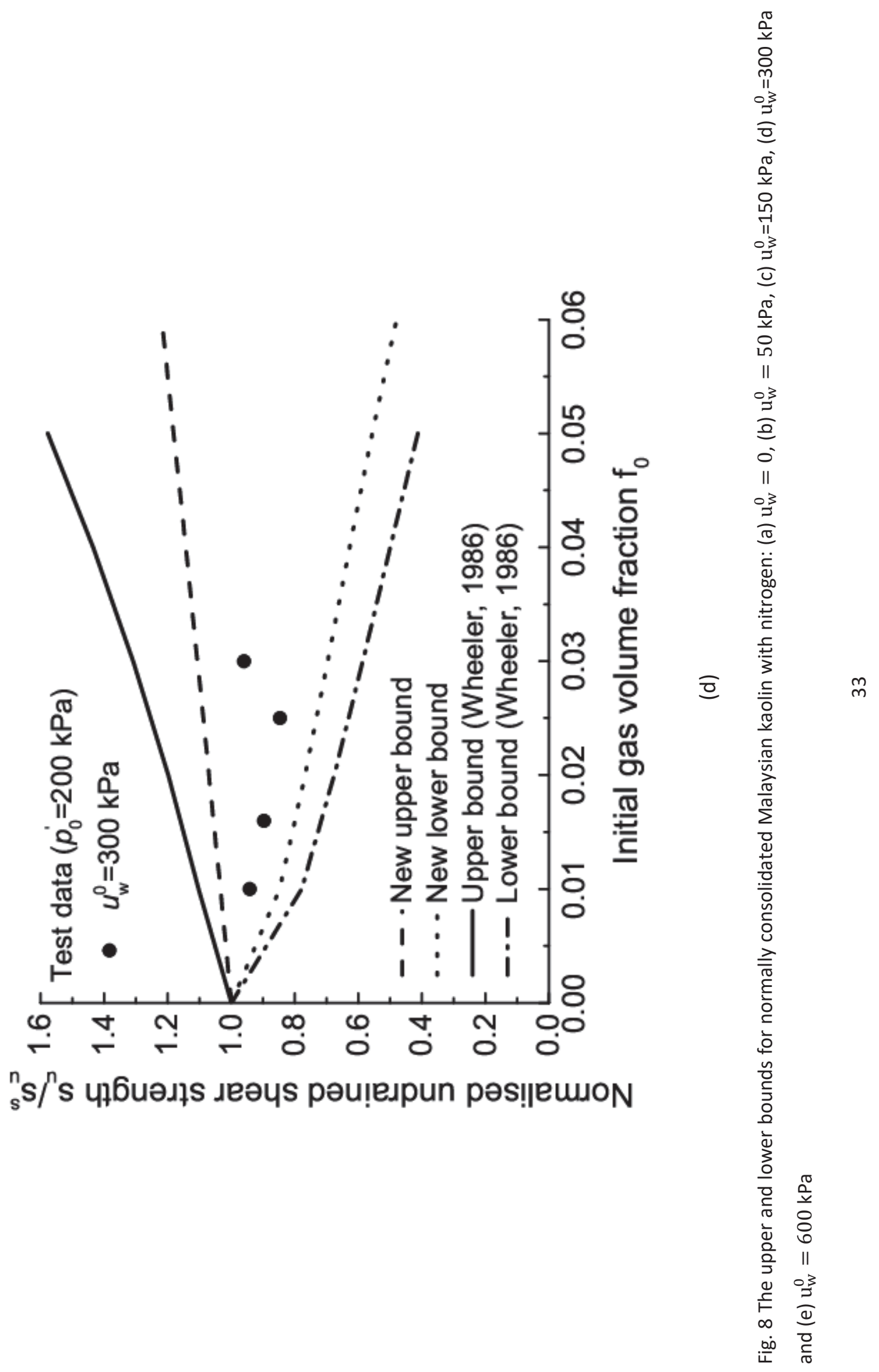




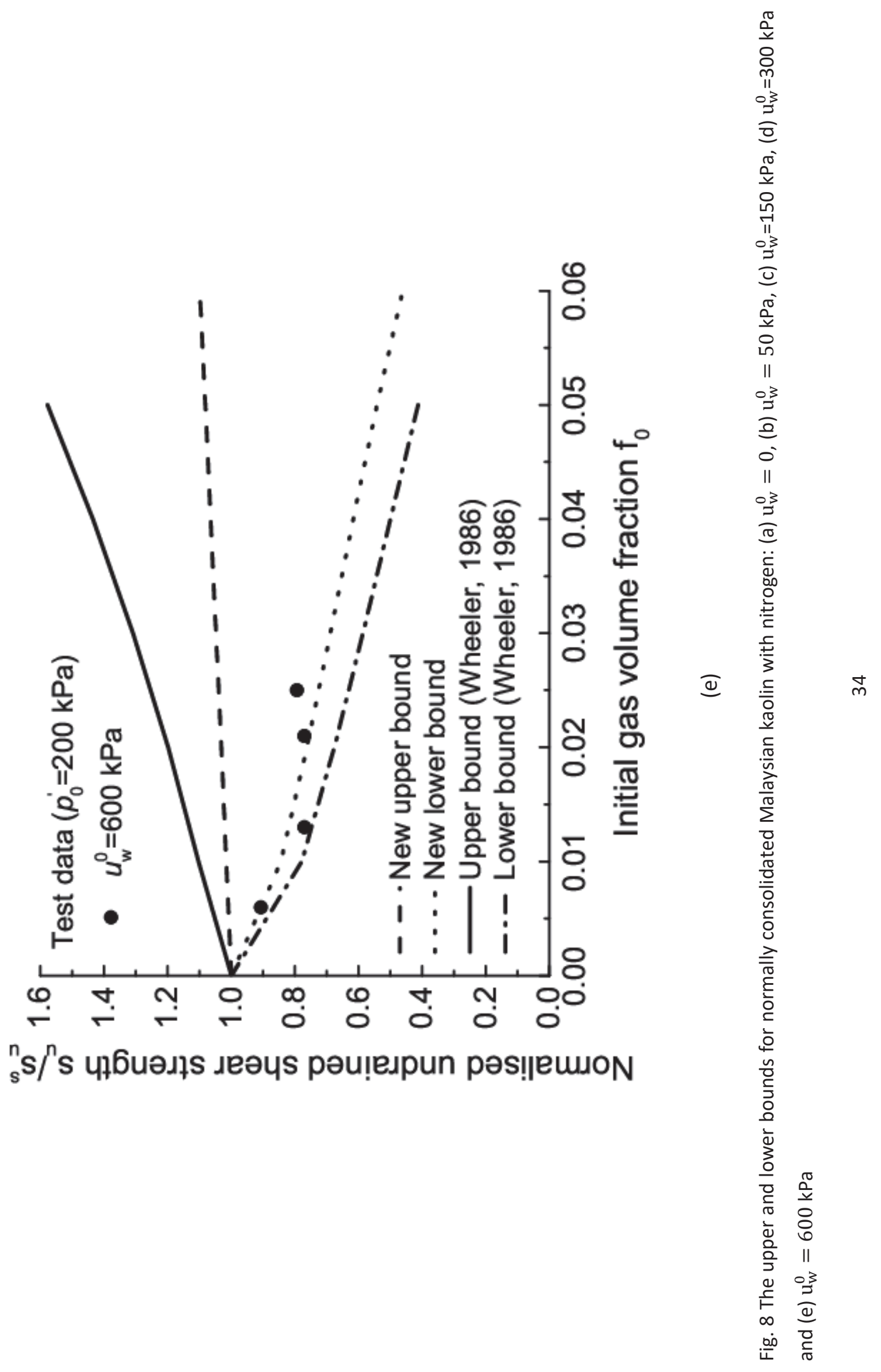




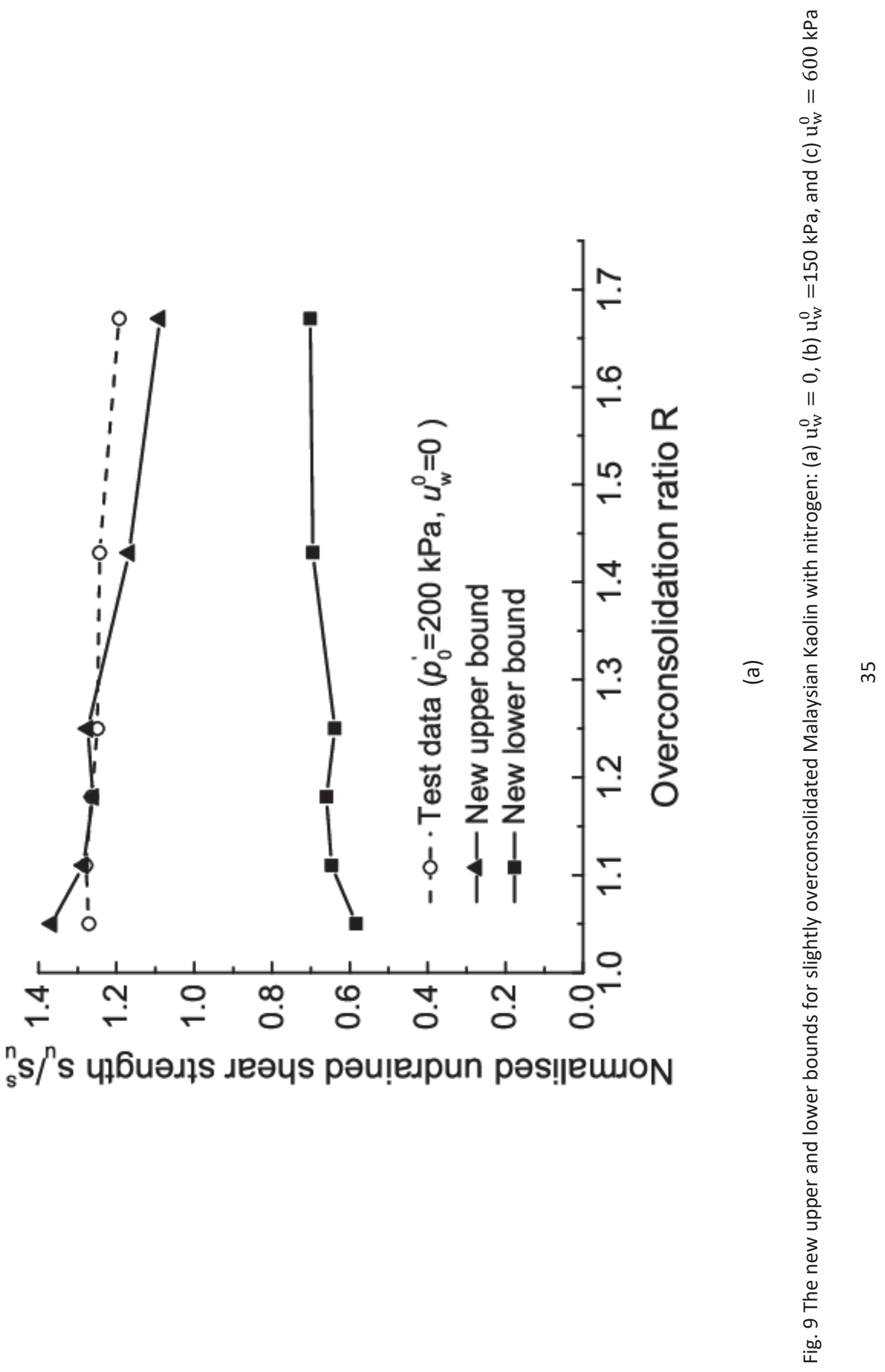




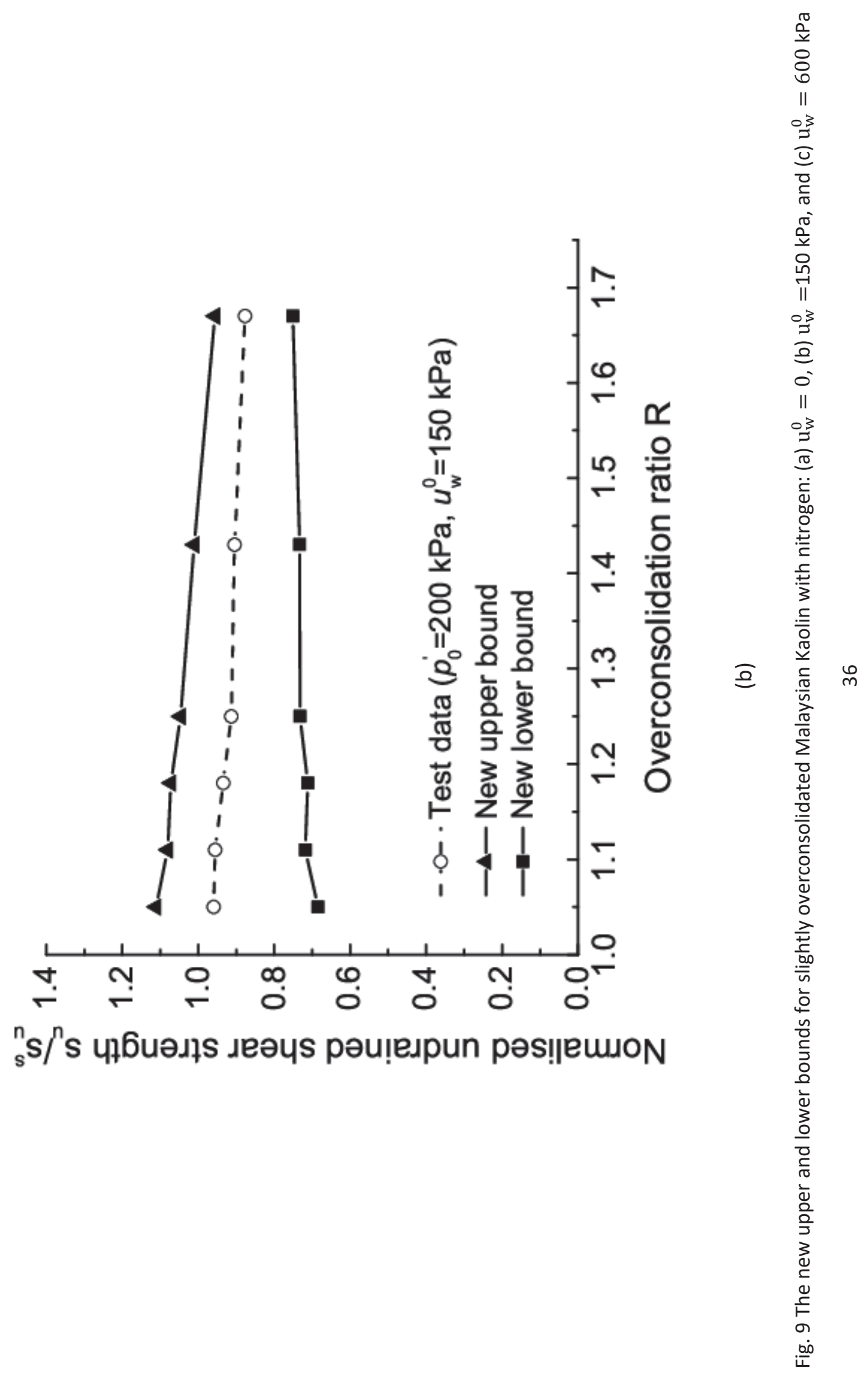




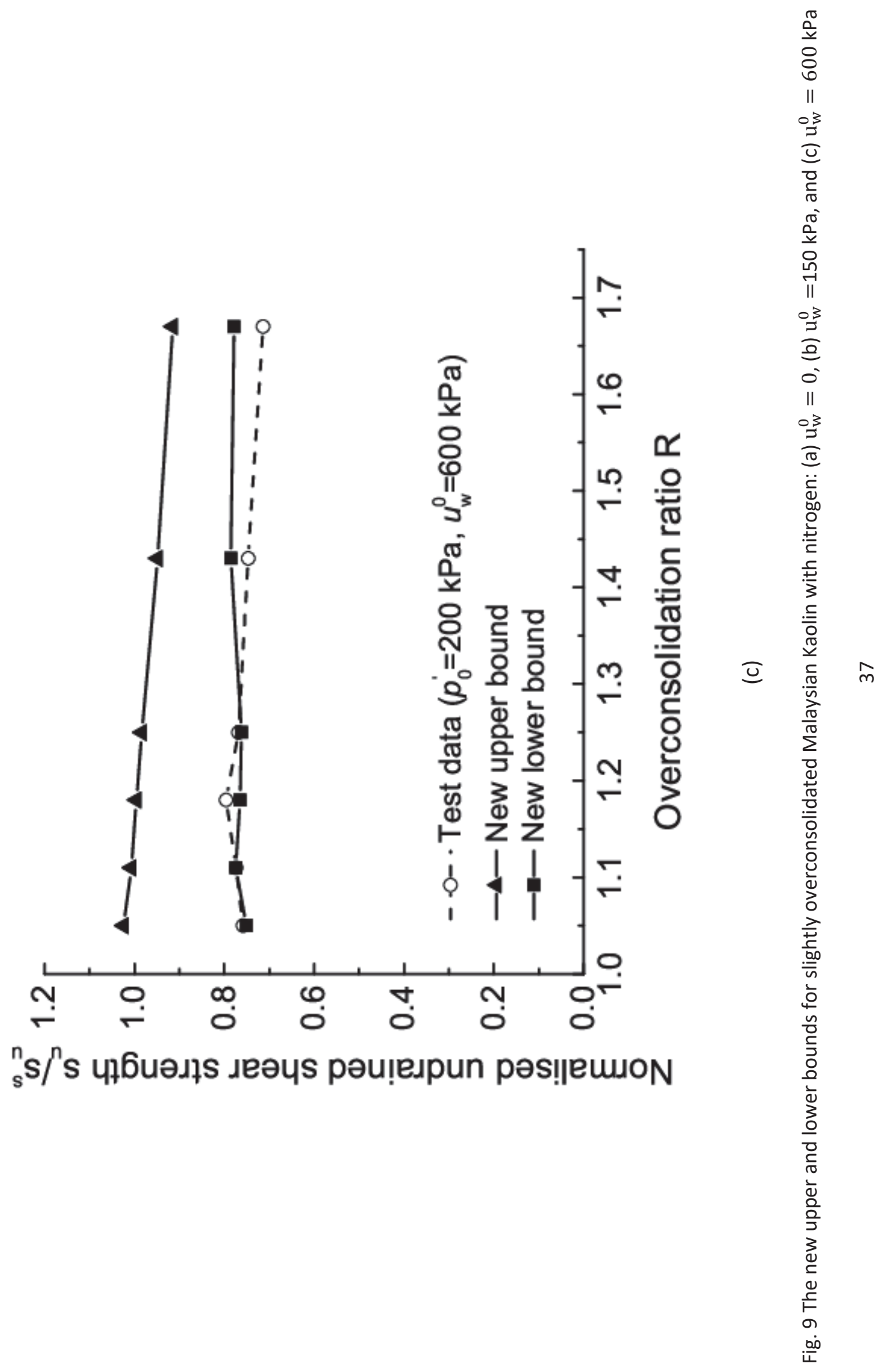




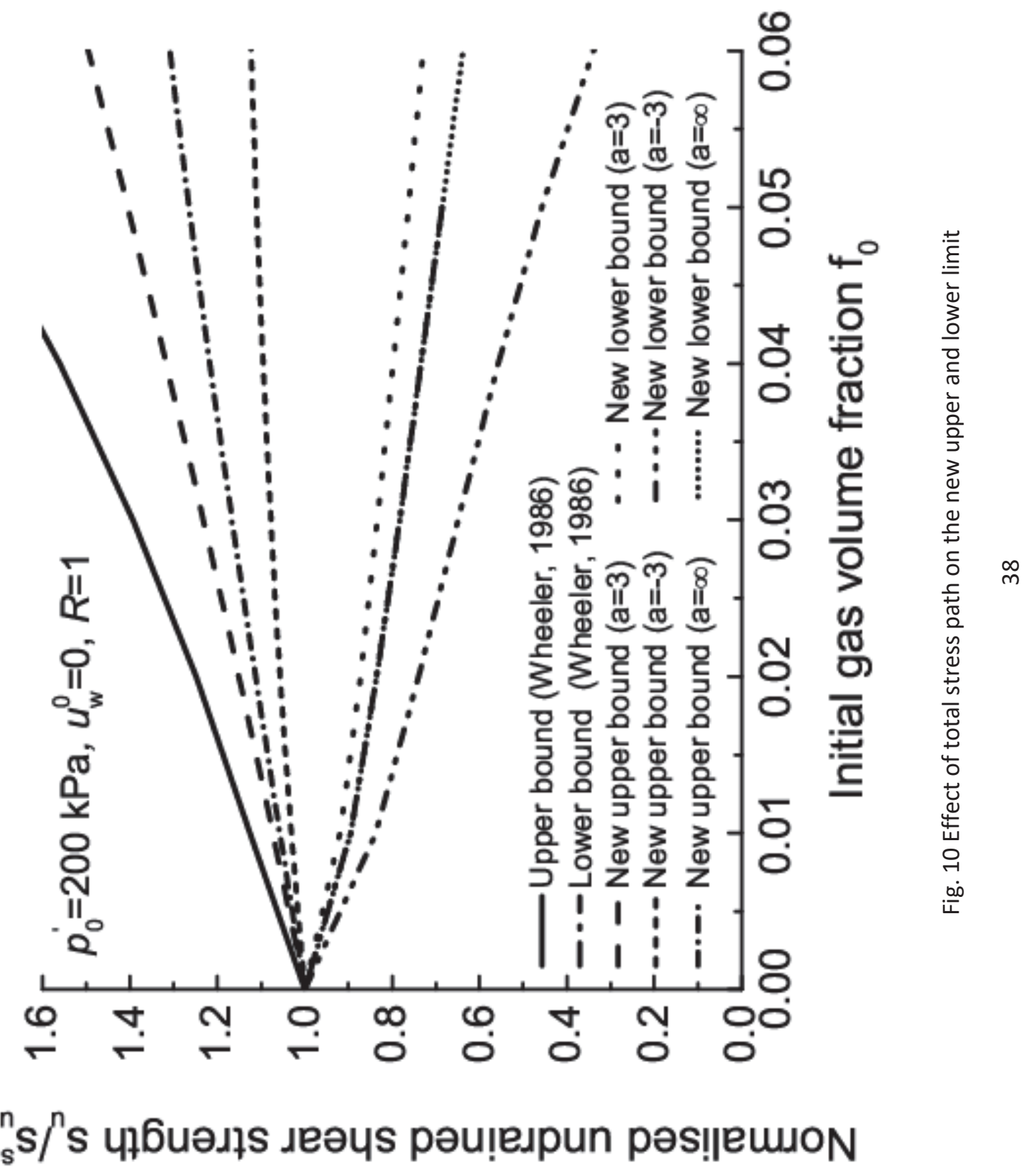

